\title{
High performance unsaturated polyester based nanocomposites: Effect of vinyl modified nanosilica on mechanical properties
}

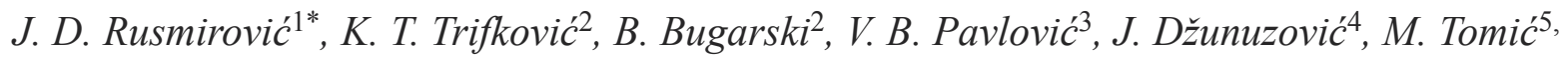 \\ A. D. Marinković6 \\ ${ }^{1}$ Innovation Center, Faculty of Technology and Metallurgy, University of Belgrade, 11120 Belgrade, Serbia \\ ${ }^{2}$ Faculty of Technology and Metallurgy, Department of Chemical Engineering, University of Belgrade, Karnegijeva 4, \\ 11120 Belgrade, Serbia \\ ${ }^{3}$ Faculty of Agriculture, Department of Mathematics and Physics, University of Belgrade, Nemanjina 6, \\ 11080 Belgrade-Zemun, Serbia \\ ${ }^{4}$ Institute of Chemistry, Technology and Metallurgy (ICTM) - Center of Chemistry, University of Belgrade, \\ Studentski trg 12-16, 11000 Belgrade, Serbia \\ ${ }^{5}$ Faculty of Technology and Metallurgy, Department of General and Inorganic Chemistry, University of Belgrade, \\ Karnegijeva 4, 11120 Belgrade, Serbia \\ ${ }^{6}$ Faculty of Technology and Metallurgy, Department of Organic Chemistry, University of Belgrade, Karnegijeva 4, \\ 11120 Belgrade, Serbia
}

Received 22 June 2015; accepted in revised form 19 September 2015

\begin{abstract}
Influences of the vinyl modified nanosilica Aerosil ${ }^{\circledR}$ 380, i.e., vinyl and methacryloyl silane coupling agent and linseed oil fatty acids (BD) reactive residues, on the mechanical properties of the unsaturated polyester resins (UPes) based nanocomposites, was studied. The polycondensation of maleic anhydride and products of poly(ethylene terephthalate) (PET) depolymerization with propylene glycol, with and without separation of ethylene glycol, yields UPe1 and UPe2 resin, respectively. The hydroxyl terminated PET depolymerization products (glycolyzates) and UPes were characterized by acid and hydroxyl values, Fourier Transform Infrared (FTIR) and nuclear magneti resonance (NMR) spectroscopies. Transmission electron microscopy (TEM) confirmed that silica nanoparticles formed domains of aggregates in the polymer matrix. An increase from 195 to $247 \%$ of stress at break $\left(\sigma_{\mathrm{b}}\right)$, and from 109 to $131 \%$ of impact strength $\left(\sigma_{\mathrm{i}}\right)$ of UPes based nanocomposites was obtained for $1 \mathrm{wt} \%$ addition of vinyl modified silica. Flexural strength $\left(\sigma_{\mathrm{f}}\right)$ increase from 106 to $156 \%$ for both UPes based nanocomposites with $1 \mathrm{wt} \%$ addition of BD modified silica. Cross-linking density (v), storage modulus $\left(G^{\prime}\right), \tan \delta$ and $T_{\mathrm{g}}$ of the nanocomposite were determined from the dynamic mechanical testing and discussed in relation to the structure of silica modification.
\end{abstract}

Keywords: nanocomposites, material testing, poly(ethylene terephthalate) recycling, unsaturated polyester resin

\section{Introduction}

Poly(ethylene terephthalate) (PET), as one of the most used engineering thermoplastic, has wide application in automobile industry, electrics, food packaging, bottle containers and textile industry, causing the increase of the world consumption of PET twice in a period of ten years [1]. The widespread use of PET imposes solution of the plastic waste problem through recycling and reprocessing method classified as primary, secondary, tertiary and quaternary recycling [2]. The products of tertiary PET recycling, especially glycolytic PET depolymerization

\footnotetext{
${ }^{*}$ Corresponding author, e-mail: jrusmirovic@tmf.bg.ac.rs

(c) BME-PT
} 
products, can be used as raw materials for production of new ones, such as different oligomers [3, 4], unsaturated polyester and vinyl ester resins $[5,6]$ and alkyd resins $[7,8]$.

The increased need for multifunctional materials with improved properties, such as high strength performance, good thermal, mechanical and physical properties, gas barrier, transparency and safety induced the development of various polymer-inorganic nanocomposites for different applications [9, 10]. By incorporation of modified inorganic nanoparticles in polymer matrices, new reinforced materials with integrated polymer matrix functionalities were obtained, such as low weight and easy processing, and unique features of the nanoparticles, such as high surface area and energy [11]. One of the reinforced materials, with a wide range of industrial applications, is unsaturated polyester resin (UPe) loaded with nanofillers such as titanium oxide [12], organochemically modified silicone oxide particles [13-15] or inorganic/organic modified multi-walled carbon nanotubes [16]. A significant improvement of mechanical and thermal properties of nanocomposite materials, obtained by the addition of silica in polymer [17-19], is caused by strong interactions between silica nanoparticles and strong filler crosslinking [20]. The main application problem of bare silica is hydrophilic surface which reduces compatibility with polymer matrix causing agglomeration, and thus it is recommended to perform appropriate modification of the silica nanoparticles [21]. A good filler dispersion, stability and compatibility with the polymer matrix can be obtained by chemical surface modification of hydroxyl groups with organosilanes [20, 22], which provides enormous possibility for new functionalities introduction. Kim and White [23] used organosilanes having different aliphatic chain lengths for silica surface chemical treatment. By organo-chemical silica modification, hybrid nanoparticles (spherical brushes) with reduced chains steric crowding were obtained [24]. The strong interaction between reinforcements and the polymer matrix distinguishes the modified silica particles from other nanoparticles $[25,26]$. Luo and coworkers [27] have studied the mechanical and thermal properties of the 3-methacryloyloxypropyl trimethoxy silane modified silica nanoparticles reinforced polyurethane (PU) coatings. Their results showed that the mechanical and thermal properties of PU coatings reinforced by modified silica nano- particles were enhanced remarkably and the tensile strength $(\delta)$ and Young's modulus $(E)$ of PU films containing $1.5 \mathrm{wt} \%$ modified silica were increased up to 64.2 and $2535.9 \mathrm{MPa}$, respectively [27].

In this work, mechanical properties of hybrid composite materials prepared by using UPes, based on glycolyzates and chemically modified silica nanoparticles with vinyl reactive functionalities: vinyl, methacryloyl and linseed oil fatty acids reactive residues, were investigated. UPe1 and UPe2 were synthesized from hydroxyl functionalized products, obtained by catalytic PET glycolysis with propylene glycol with and without azeotropic removal of ethylene glycol, respectively, and maleic anhydride. The mechanical and dynamic-mechanical properties of the obtained nanocomposites were determined, and obtained results were discussed in relation to properties of used UPes, modified silica content and structural properties and reactivity of vinyl based functionalities introduced at nanosilica surface.

\section{Experimental section \\ 2.1. Materials and sample preparation \\ 2.1.1. Materials}

Waste PET, used for unsaturated polyester resin production, was collected from soft beverage bottles. PET bottles were crushed into small pieces (app. $0.5 \times 0.5 \mathrm{~cm}$ ) and washed with ethanol and dichloromethane to remove impurities and residual adhesives. Propylene glycol (1,2-propanediol) and ethylene glycol were purchased from Riedel-de Haën Seelze-Hannover (Sigma-Aldrich, Darmstadt, Germany). Xylenes (mixture of 1,2-, 1,3- and 1,4dimethyl-benzene), tetrabutyl titanate (TBT), dichloromethane (DCM), (3-aminopropyl)trimethoxysilane 97\% (APTMS), 3-(trimethoxysilyl) propyl methacrylate (TMSPM) and tris(2-methoxyethoxy)(vinyl)silane (TMEVS) were purchased from Fluka (Sigma-Aldrich, Darmstadt, Germany). Styrene, toluene, pyridine, 2-butanone peroxide (methyl ethyl ketone peroxide; MEKP), cobalt octoate (Co-oct), maleic anhydride (MA), hydroquinone (HQ), methanol, absolute ethanol, terephthaloyl dichoride and tetrahydrofuran (THF) were obtained from Sigma-Aldrich (Sigma-Aldrich Darmstadt, Germany). Fumed silica, with trade name Aerosil ${ }^{\circledR} 380$, was kindly provided by Evonik (Evonik industries, Essen, Germany). Aerosil ${ }^{\circledR} 380$ is hydrophilic fumed silica with a specific surface area of $380 \mathrm{~m}^{2} / \mathrm{g}$. 


\subsubsection{Glycolysis of PET}

\section{a) Classical method}

The classical method for PET glycolysis have recently been described elsewhere [15]. Molar ratio of waste PET and PG used for glycolysis was 1.0:1.5.

\section{b) Ethylene glycol (EG) removal method}

Following the procedure of classical method for PET glycolysis (2.1.2. a)), new synthesis of PET glycolyzate was done with the succeeding modification by EG azeotropic removal method [15]. Continual monitoring, by the use of gas chromatography method (GC), of the EG/PG content in the bottom layer of Dean-Stark was used for quantification of time-dependent removal of PG. Azeotropically separated PG was compensated by addition appropriate quantity of $P G$ into reaction mixture to maintain approximately 1.0/1.5 PG/PET initial molar ratio according to the calculated extent of reaction. Continual decreases of EG was observed from GC chromatogram, and when no more EG was found (app. 91\% extent of reaction), excess of PG was azeotropically removed, placed in a vacuum oven $\left(100^{\circ} \mathrm{C} /\right.$ $2000 \mathrm{~Pa}$ ) and then the obtained reaction product was hot filtered.

By application of both glycolysis methods, products of various compositions were obtained. In the case 2.1.2. a) glycolyzate consisted of a mixture of PG symmetrical and asymmetrical glycol esters of terephthalic acid: bis(2-hydroxylpropyl) terephthalate and bis(1-hydroxypropan-2-yl) terephthalate, as well as (2-hydroxyethyl) (2-hydroxypropyl) terephthalate (main component)) and free glycols, EG and PG. Product obtained by method 2.1.2. b) is mainly composed of PG symmetrical and asymmetrical glycol esters of terephthalic acid.

\subsubsection{Synthesis of $\mathbf{E G}$ ester of terephthalic acid - bis(2-hydroxyethyl)terephthalic acid}

For synthesis of terephthalic acid ester, previously described in detail [15], was used $3.7 \mathrm{~g},(0.06 \mathrm{~mol})$ of EG dry solution, $1.58 \mathrm{~g}$, $(0.02 \mathrm{~mol})$ of dry pyridine in $50 \mathrm{~mL}$ of dry THF and a solution of terephthaloyl dichoride (2.03 g, $0.01 \mathrm{~mol})$ in $50 \mathrm{~mL}$ of dry THF. The bis(2-hydroxy propyl)terephthalate was synthesized analogously to bis(2-hydroxy-ethyl)terephthalate. The characterization of the obtained products of glycolysis was performed by FTIR, ${ }^{1} \mathrm{H}$ and
${ }^{13} \mathrm{C}$ NMR, and elemental analysis [28], and used as standard for HPLC analysis.

\subsubsection{Synthesis of unsaturated polyesters resin (UPeN) based on PET glycolyzates}

a) UPe1

After completion of the glycolysis reaction (product obtained by classical method - 2.1.2. a)), keeping inert atmosphere, mixture was cooled down to $90^{\circ} \mathrm{C}$ and the Dean-Stark separator was assembled. MA (123 g, $1.25 \mathrm{~mol})$ and half of the required amount of HQ ( $0.03 \mathrm{~g}$ dissolved in $2 \mathrm{mLof}$ ethanol) were charged into glass reactor, whereupon the mixture was heated to $115^{\circ} \mathrm{C}$ at constant temperature for $1 \mathrm{~h}$. Afterwards, continuous temperature increase was achieved at a heating rate of $15^{\circ} \mathrm{C} / \mathrm{h}$ until $150^{\circ} \mathrm{C}$, when the toluene $(6 \mathrm{wt} \%)$ was added as the agent for azeotropic removal of water. The temperature increase was continued until $210^{\circ} \mathrm{C}$. The reaction was conducted until the acid number value decreased below $30 \mathrm{mg} \mathrm{KOH} / \mathrm{g}$, after which the resin obtained was cooled down to $120^{\circ} \mathrm{C}$ and a solution of the $0.03 \mathrm{~g} \mathrm{HQ}$ in $2 \mathrm{~mL}$ of methanol was added. After the completion of the reaction, the low boiling compounds were removed from the reaction product by vacuum distillation. The vacuum distillation was carefully applied for 1 hour, and the obtained resin was cooled down to $100^{\circ} \mathrm{C}$ and dissolved in styrene (40 wt\%) containing equivalent amount of inhibitor.

\section{b) $\mathrm{UPe} 2$}

The synthesis of unsaturated polyester resin (UPe2) from the glycolysis product obtained by ethylene glycol azeotropic removal method was performed in an analogous manner as described in method 2.1.4. a).

\subsubsection{Synthesis of methyl ester of linseed oil fatty acid (biodiesel - BD)}

In a four-necked glass reactor of 21 , equipped with a reflux condenser, mechanical stirrer, thermometer and dropping funnel, $929 \mathrm{~g}(3.3 \mathrm{~mol})$ of linseed oil, dissolved in $85 \mathrm{~mL}$ of methanol, was added. The potassium hydroxide solution in methanol $(0.12 \mathrm{~mol}$ of $\mathrm{KOH}$ in $102 \mathrm{~mL}$ of methanol) was added drop wise. Afterward, the reaction mixture was heated at 58$62^{\circ} \mathrm{C}$ for 3 hours, and left to cool down. Bottom layer, i.e. mainly raw glycerin, was separated, and upper layer was treated with active charcoal and filtered 
through diatomaceous earth. After drying with sodium sulfate, the obtained linseed oil methyl ester (biodiesel) was purified by vacuum distillation under nitrogen. Characteristics of methyl ester of linseed oil fatty acid mixture, named BD: acid value $(A V)$ $5 \mathrm{mg} \mathrm{KOH} / \mathrm{g}$; ester content $97 \%$; iodine value 152 .

\subsubsection{Chemical modification of Aerosil ${ }^{\circledR} 380$}

Three types of silane coupling agents containing vinyl, methacryloxy and unsaturated fatty acid residues were used for silica functionalization in order to study the influence of silica modification on the mechanical properties of the UPe based nanocomposites. It was proved that modified nanoparticles behave beneficially within polymer matrices in comparison to unmodified ones, e.g., the modified nanoparticles show comparatively better dispersion in polymer, accompanied with covalent bonding, which could significantly improve nanocomposite properties $[20,22]$. In order to achieve these goals, modification of Aerosil ${ }^{\circledR} 380$ was performed by covalent bonding with unsaturated fatty acid residues to silica surface by a two-step method:

\section{a) First step; modification with \\ (3-aminopropyl)trimethoxysilane}

In a dry three-necked glass reactor, equipped with a magnetic stirrer, reflux condenser, thermometer and a nitrogen inlet tube, $1.0 \mathrm{~g}$ of silica (Aerosil ${ }^{\circledR} 380$ ) and $120 \mathrm{~mL}$ of dry toluene were charged. After dispersion of silica in toluene under ultrasound for $5 \mathrm{~min}, 3.97 \mathrm{~g}$ of (3-aminopropyl)trimethoxysilane was added and the modification reaction was continued for 48 hours at $25^{\circ} \mathrm{C}$ under the nitrogen atmosphere. Ultrasonic bath (Bandelin electronic, Berlin, Germany, power $120 \mathrm{~W}$, frequency $35 \mathrm{kHz}$ ) was thermostated by circulating water through the jacket, and used for silane modification as well as for preparation of nanocomposite. The modified silica was separated from solution by vacuum filtration, and the filter cake was washed twice with the toluene, and then dispersed in $120 \mathrm{~mL}$ of toluene using ultrasonic bath.

\section{Second step of silica modification with $B D$}

The modified silica with terminal amino group, from the first step of silica modification, was dispersed in $50 \mathrm{~mL}$ THF and $1.56 \mathrm{~g}$ of methyl ester of linseed oil fatty acids were charged in a three-necked glass reactor, equipped with a magnetic stirrer, ther- mometer, reflux condenser and calcium chloride protection tube. The reaction took place for $12 \mathrm{~h}$ at $25^{\circ} \mathrm{C}$, whereupon the mixture was heated to $60^{\circ} \mathrm{C}$ and maintained for 2 hours. The obtained product, named R380BD, was filtered under the vacuum, two times re-dispersed in THF and filtered, washed with absolute ethanol and dried at $40^{\circ} \mathrm{C}$ for $12 \mathrm{~h}$.

\section{b) Silica modification with \\ 3-(trimethoxysilyl)propyl methacrylate}

The modification of fumed silica nanoparticles with TMSPM was done in an analogues manner to the procedure 2.1.6. a). Obtained product was named R380MA.

\section{c) Silica modification with \\ tris(2-methoxyethoxy)(vinyl)silane}

In an analogues manner to the procedure 2.1.6. b), the modification of fumed silica nanoparticles with TMEVS was performed. Obtained product was named R380V.

\subsubsection{Preparation of nanocomposites based on UPeN and chemically modified silica by solution dispersion (blending) method}

Nanocomposites based on UPeN and chemically modified silica nanoparticles were prepared using solution blending method. The UPes were used as the polymeric matrix and the modified silica nanoparticles, dispersed in styrene, were used as filler for nanocomposite preparation. The nanocomposites, UPeN/R(n), were obtained by processing of appropriate amounts of binder, UPeN resin, and dispersed nanofillers, modified silica nanoparticles. Index $\mathrm{N}$ designates UPe resin (described in exp. 2.1.4.)), index $\mathrm{R}$ designates the silica modification (R380BD, R380MA and R380V designates APTMSBD, TMSPM and TMEVS modification of Aerosil ${ }^{\circledR}$ R380, respectively); index (n) designates the percent of the addition of modified silica nanoparticles: 0.1 (a), 0.5 (b), 1.0 (c) and 2.0 (d) [wt \%] in nanocomposites. The homogenization of fumed silica with UPeN (60 wt \% in styrene) was achieved by using modified laboratory homogenizer and an ultrasonic bath. The pure UPeN (60 $\mathrm{wt} \%$ in styrene) and nanocomposites UPeN/R(n) were cured using $\operatorname{MEKP}(1 \mathrm{wt} \%)$ as the initiator and Co-oct $(0.5 \mathrm{wt} \%)$ as the accelerator. Schematic illustration of the preparation and intermolecular interactions in crosslinked UPeN/R nanocomposites is given in Figure 1. 


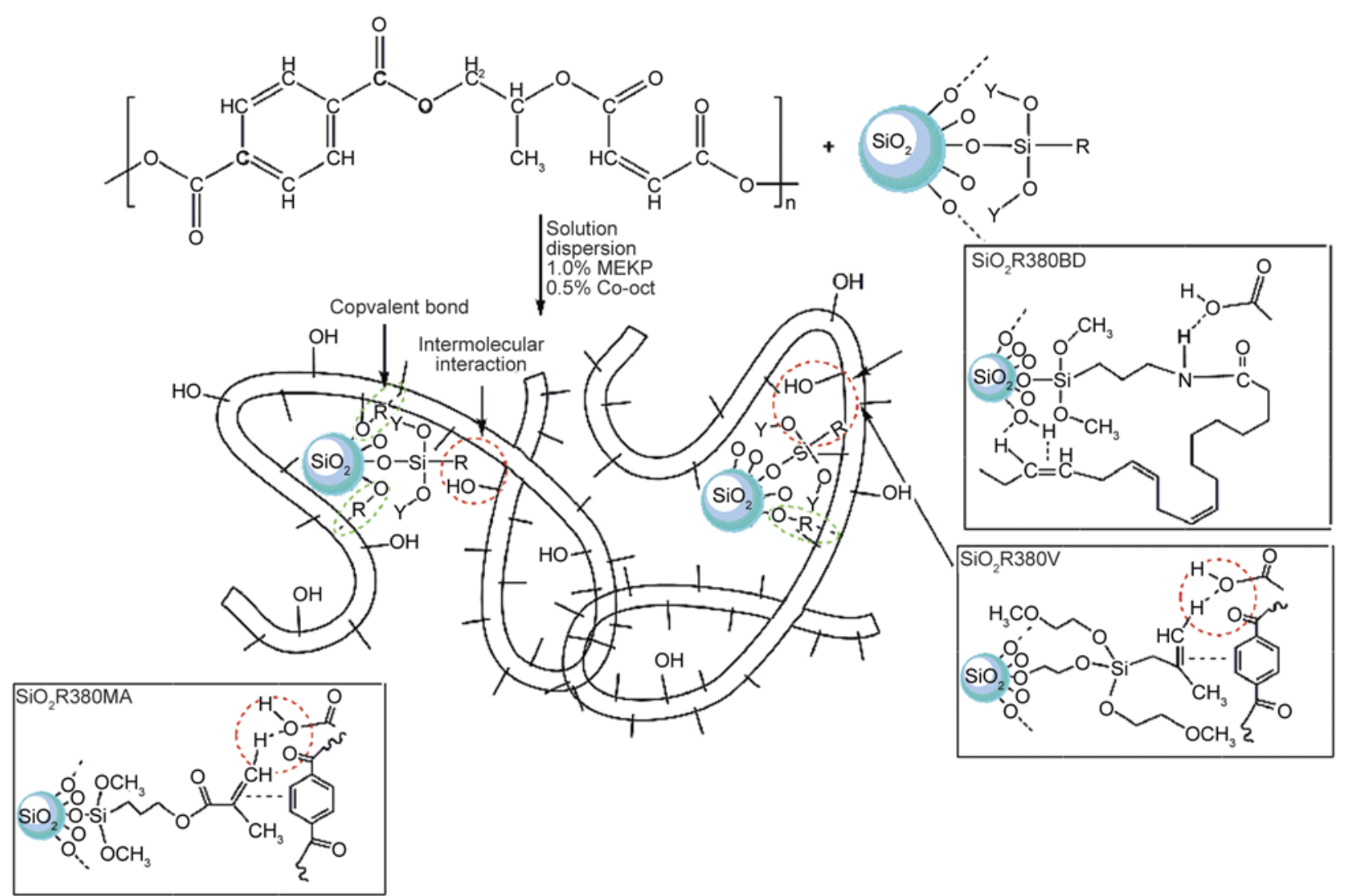

Figure 1. Preparation of nanocomposites with proposed reinforcing interactions between modified silica nanofiller and UPe matrix

Hydrophylicity of Aerosil ${ }^{\circledR} 380$ surface, due to coverage by hydroxyl groups, contributes to the lower silica compatibility with UPe matrix and small reinforcing effect in the nanocomposite. The design of silica surface involved modification with vinyl based silane coupling agents and $\mathrm{BD}$ reactive residues, to achieve better nanofiller dispersibility and reinforcement of prepared nanocomposite. Vinyl containing surface moieties provide, in addition to the cross-linking reactivity during curing, compatibility and physical reinforcing due to the existence of different intermolecular interactions: $\pi, \pi$-stacking, dipolar and hydrogen bonding interactions (Figure 1). Also, spatial conformations of the fatty acid residue, due to pronounced flexibility could form spherical wrapped structure stabilized by hydrogen like bonding interactions, and in that way influence availability of ethylene groups to participate in crosslinking reaction during nanocomposite curing.

\subsection{Experimental techniques}

The structural analysis of the obtained glycolyzed product and synthesized polyesters was performed by Fourier transform infrared (FTIR) (Bomem MB-
102) spectroscopy, within a range of $400-4000 \mathrm{~cm}^{-1}$, at a resolution of $4 \mathrm{~cm}^{-1}$. ${ }^{1} \mathrm{H}$ and ${ }^{13} \mathrm{C}$ nuclear magnetic resonance (NMR) spectra of UPeN were recorded in deuterated chloroform $\left(\mathrm{CDCl}_{3}\right)$, using a VarianGemini 2000 spectrometer at $200 \mathrm{MHz}$ for the ${ }^{1} \mathrm{H}$ NMR and $50 \mathrm{MHz}$ for the ${ }^{13} \mathrm{C}$ NMR spectra. Varian 3400 gas chromatography with DB5 column and flame ionization detector was used for analysis of EG/PG mixture. Evaluation of the composition of glycolysis products was performed by high performance liquid chromatography using Spectra System P4000, column Zorbax SB-C8 and mobile phase acetonitrile/methanol (60/40) (isocratic mode).

The hydroxyl value $(H V)$ was determined using a conventional acetic anhydride/pyridine method (ISO 4326:1992) [29]. The acid value ( $A V$ ) was determined using a standard method ASTM D3644 [30]. Ester value (EV) was determined using European quality standard for fatty acid methyl esters E14103 [31]. Number average molecular weight was calculated according to the Equation (1):

$M_{\mathrm{n}}=\frac{2 \cdot 56100}{A V+H V}$ 
Iodine value was determined by the Wijs method. Elemental analyses were performed using a VARIO EL III Elemental analyzer.

The viscosity measurement of the UPeN, $60 \mathrm{wt} \%$ styrene solution, was carried out at $25^{\circ} \mathrm{C}$, using Ford viscosity cup 4 (ASTM D1200) [32]. The gel time of the samples was determined from the cure exotherm which was measured according to ASTM D2471-99 [33].

Microstructural (morphological) characterization of the UPeN/R(n) nanocomposites was performed on a transmission electron microscope (TEM) JEM1400 .

Uniaxial tensile measurements of standard cured samples (ASTM D882) [34] were performed using an AG-X plus Universal testing machine, Shimadzu. All tests were performed at room temperature adjusted at crosshead speed of $0.5 \mathrm{~mm} / \mathrm{min}$. The flexural properties were measured by the Instron (Model 1332) as per ASTM D 790 [35]. The support span length was set at $45 \mathrm{~mm}$. The testing speed was set at $1.5 \mathrm{~mm} / \mathrm{min}$. The impact strength was measured by Karl Frank GMBH Weinheim - Birkenau; Type 5330, Werk - Nr 29680 as per ASTM D 256 [36].

Thermogravimetric analysis (TGA) was performed using a Seteram Setsys Evolution-1750 instrument. The TGA experiments were run in a nitrogen atmosphere (flow rate $25 \mathrm{~cm}^{3} / \mathrm{min}$ ) from 30 to $800^{\circ} \mathrm{C}$, with a heating rate of $10^{\circ} \mathrm{C} / \mathrm{min}$.

The mechanical properties and glass transition temperature $\left(T_{\mathrm{g}}\right)$ of unsaturated polyester composites were obtained using dynamic-mechanical analysis, which was performed on a Discovery Hybrid Rheometer HR2 (TA Instruments). The dynamic-mechanical analysis was conducted in a torsion rectangular mode (dimensions: $6 / 1 / 0.2$ ) from 25 to $120^{\circ} \mathrm{C}$ at fixed strain amplitude of $0.1 \%$ and angular frequency of $1 \mathrm{~Hz}$. The results are presented as mechanical spectra by monitoring the dependence of the storage $\left(G^{\prime}\right)$ and loss $\left(G^{\prime \prime}\right)$ shear modulus and loss or damp- ing factor $\tan \delta\left(G^{\prime \prime} / G^{\prime}\right)$ on temperature. Differential scanning calorimetric (DSC) measurements were performed using Setaram151 R instrument in the temperature range $30-200^{\circ} \mathrm{C}$.

\section{Results and discussion \\ 3.1. Glycolysis of PET with PG}

Various oligoesters (glycolysis products) can be obtained by PET de-polymerization using different glycols like ethylene glycol, diethylene glycol, propylene glycol, polyethylene glycol, 1,4-butanediol, hexylene glycol, etc. [37]. Güclü et al. [38] have investigated glycolysis of waste PET with PET/EG or PET/ PG molar ratio of 1.0:0.5 to 1.0:3.0 in xylene. They have found that the PET glycolysis in xylene was a multiphase reaction in which formed oligomers transferred from PET/glycol dispersion to xylene medium at elevated temperature. The best glycolysis monomer/dimer ratio was found at $220^{\circ} \mathrm{C}$.

The glycolysis reaction of waste PET with PG was catalyzed with TBT and the hydroxy-terminated products of glycolysis PET were obtained. Table 1 displays $H V, A V$ values and results of elemental analysis of the glycolyzed products obtained by methods 2.1.2. a) and 2.1.2. b).

The higher oxygen content of the product obtained by method 2.1.2. a), found from elemental analysis and $H V$ values (Table 1), confirms that the glycolysis products in the case 2.1.2. a) consisted of the mixture of glycol esters of terephthalic acid: bis(2hydroxylpropyl) terephthalate, (2-hydroxyethyl)(2hydroxypropyl)terephthalate (main product - 55$60 \%$ ) and free glycols. Due to the azeotropic removal of excess of PG and liberated EG, product of glycolysis, obtained by method 2.1.2. b), contains mainly bis(2-hydroxylpropyl)terephthalate and minor (less than $5 \%$ ) fraction of (2-hydroxyethyl)(2-hydroxypropyl)terephthalate. These results were evaluated from HPLC analysis of glycolysis products obtained by methods 2.1.2. a) and b). Characterization of the products of glycolysis was essential for understand-

Table 1. $H V, A V$ values and results of elemental analysis of glycolyzed products (PG ester of terephthalic acid)

\begin{tabular}{|c|c|c|c|c|c|c|c|}
\hline Method & $\begin{array}{c}H V_{\text {theor. }}^{k} \\
{[\mathrm{mg} \mathrm{KOH/g]}}\end{array}$ & $\begin{array}{c}H V_{\text {exp. }} \\
{[\mathrm{mg} \mathrm{KOH} / \mathrm{g}]}\end{array}$ & $\begin{array}{c}A V_{\text {exp. }} \\
{[\mathrm{mg} \mathrm{KOH} / \mathrm{g}]}\end{array}$ & & $\% \mathrm{C}$ & $\% \mathrm{H}$ & $\% \mathrm{O}^{* *}$ \\
\hline \multirow{2}{*}{ 2.1.2. a) } & \multirow{2}{*}{418} & \multirow{2}{*}{302} & \multirow{2}{*}{5} & Exp. & 57.85 & 6.16 & 35.98 \\
\hline & & & & Calc. & 58.20 & 6.01 & 35.78 \\
\hline \multirow{2}{*}{ 2.1.2. b) } & \multirow{2}{*}{397} & \multirow{2}{*}{274} & \multirow{2}{*}{4} & Exp. & 59.04 & 6.70 & 34.26 \\
\hline & & & & Calc. & 59.57 & 6.43 & 34.00 \\
\hline
\end{tabular}

${ }^{*}$ Theoretical $H V$ value was calculated in relation to the theoretical number of hydroxyl groups of PG, recalculated to the molar mass of the product of glycolysis; ${ }^{* *}$ Oxygen percent was calculated as subtraction 
ing/establishing the structure/properties (reactivity) relationships of the obtained UPeN and nanocomposites.

\subsection{FTIR analysis of glycolysis product, fumed silica, UPeN and composite materials}

The FTIR spectra of the product of PET glycolysis, obtained by method 2.1.2. b), the unmodified and modified fumed silica, and the UPeN (method 2.1.4. a) and b)) are shown in Figure 2a.

The broad peak at about $3382 \mathrm{~cm}^{-1}$ and the low intensity peak at $701 \mathrm{~cm}^{-1}$ originate from hydroxyl $(\mathrm{OH})$ groups stretching vibrations. Aromatic $\mathrm{C}-\mathrm{H}$ stretching vibrations are observed at around $2961 \mathrm{~cm}^{-1}$. Overlapped symmetric and asymmetric vibrations of methyl $\left(\mathrm{CH}_{3}\right)$ and methylene $\left(\mathrm{CH}_{2}\right)$ groups are observed at 2952 and $2854 \mathrm{~cm}^{-1}$, while their bending vibrations are observed at about 1452 and $1366 \mathrm{~cm}^{-1}$. The band at $1725 \mathrm{~cm}^{-1}$ originates from carbonyl $(\mathrm{C}=\mathrm{O})$ groups present in ester terephthalic acid. Ester $\mathrm{C}-\mathrm{O}$ stretching vibrations, asymmetric and symmetric, are observed at about 1360 and $1107 \mathrm{~cm}^{-1}$, respectively.

Characteristic adsorption peak for modified and unmodified silica nanoparticles appears at $1099 \mathrm{~cm}^{-1}$ and represents the stretching vibration of $\mathrm{Si}-\mathrm{O}-\mathrm{Si}$ bonds (Figure 2a). The $\mathrm{OH}$ stretching vibrations are observed at about $3433 \mathrm{~cm}^{-1}$ and 1636, 801 and $694 \mathrm{~cm}^{-1}$. In the FTIR spectra of different modified silica nanoparticles (methods 2.1.6. a)- c)), the adsorption peaks around 2961, 2923 and $2861 \mathrm{~cm}^{-1}$

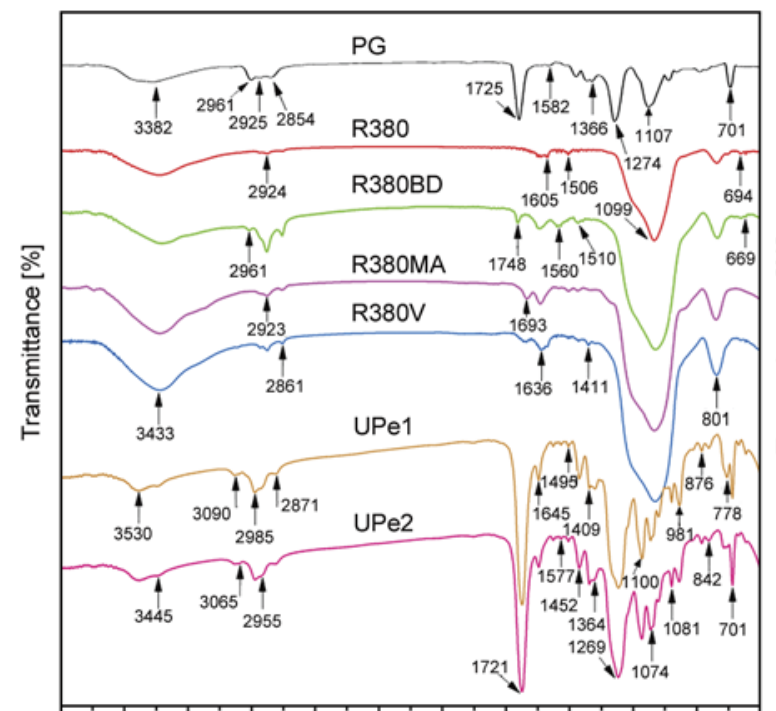

3900360033003000270024002100180015001200900600 a) Wave number $\left[\mathrm{cm}^{-1}\right]$ originate from $\mathrm{CH}_{3}$ and $\mathrm{CH}_{2}$ stretching vibrations, and peaks between 1560 and $1411 \mathrm{~cm}^{-1}$ from their bending vibrations, respectively. The bands at around 1748 and $1693 \mathrm{~cm}^{-1}$ are due to the $\mathrm{C}=\mathrm{O}$ functional groups present in the modified silica nanoparticles. The stretching $v(\mathrm{~N}-\mathrm{H})$ vibrations are observed at about $800 \mathrm{~cm}^{-1}$, and are overlapped with hydroxyl group stretching vibrations (characteristic peak for APTMS modification). The $\mathrm{C}=\mathrm{C}$ stretching vibrations are observed at around $1366 \mathrm{~cm}^{-1}$ (characteristic adsorption peak for TMSPM and TMEVS silica modification).

Qualitative estimations of the differences in the spectra of the UPeN before and after the nanofiller loading indicate the types and intensity of interactions between the matrix (functional groups at polymer chains) and the nanofiller surface functional groups. FTIR spectra of UPeN (Figure 2a) and nanocomposites based on UPeN and modified silica are similar (Figure 2b). The broad band at $>3000 \mathrm{~cm}^{-1}$ originates from hydroxyl group stretching vibrations. The narrow peaks between 2985 and $2852 \mathrm{~cm}^{-1}$ come from $\mathrm{CH}_{3}$ and $\mathrm{CH}_{2}$ stretching vibrations, respectively, and corresponding $\mathrm{CH}_{3}$ and $\mathrm{CH}_{2}$ bending vibrations appeared at 1452 and $1364 \mathrm{~cm}^{-1}$ for UPe1 and UPe2. These peaks, for nanocomposites $\mathrm{UPeN} / \mathrm{R}(\mathrm{d})$, are shifted to higher values $(\sim 1455$ and $\sim 1384 \mathrm{~cm}^{-1}$ ). The intensive peak at $1721 \mathrm{~cm}^{-1}$ is due to the stretching vibration of ester $\mathrm{C}=\mathrm{O}$ groups present in terephthaloyl moiety, and it is shifted to higher value in UPeN/R(d) $\left(1725 \mathrm{~cm}^{-1}\right)$. The bands

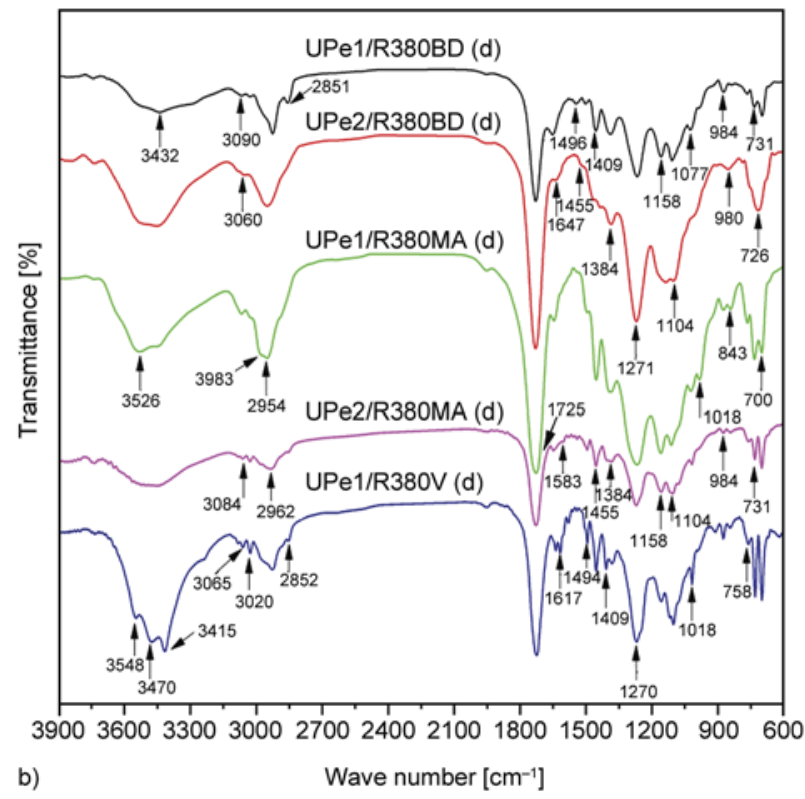

Figure 2. FTIR spectra of the glycolyzed product (marked as PG; method 2.1.2. b)), unmodified and modified silica, and UPe resins (a), and UPe1/and UPe2/R(d) nanocomposites (b) 
in the region $3090-3020 \mathrm{~cm}^{-1}$ correspond to the valence $\mathrm{C}-\mathrm{H}$ stretching vibrations. Skeletal $\mathrm{C}=\mathrm{C}$ double bond vibrations observed at $1647-1617 \mathrm{~cm}^{-1}$ correspond to the phenyl core. Two narrow adsorption peaks identified at about 731 and $700 \mathrm{~cm}^{-1}$ are assigned to the skeletal $\gamma(\mathrm{CH})$ vibrations of benzene ring, and these peaks are shifted to higher value for UPeN (778 and $\left.701 \mathrm{~cm}^{-1}\right)$. Similar results with smaller differences in FTIR spectra were found for other UPeN nanocomposites at lower nanofiller loading, and that is the reason why these results are not presented in this section.

\subsection{Thermal properties of silica nanoparticles}

The thermal properties of silica nanoparticles were examined by thermogravimetric analysis performed in a nitrogen atmosphere. The TGA and differential thermo-gravimetric (DTG) curves of unmodified Aerosil $^{\circledR} 380$ (R380) and modified nanosilica R380BD, R380MA and R380V are shown in Figure 3. From the TGA curves (Figure 3a)) it can be seen that the unmodified Aerosil ${ }^{\circledR} 380$ is stable at temperatures below $800^{\circ} \mathrm{C}$ with $1.7 \%$ weight loss. Significant difference in thermal stability between bare and modified silica nanoparticles could be observed from TGA and DTG curves.

TGA curves of modified silica nanoparticles are very similar, and the thermal degradation of all samples took place in two stages. The weight loss of all samples, in the range from room temperature to $150^{\circ} \mathrm{C}$, originates mainly from the moisture adsorbed on the surface. The further weight loss in the range $150-230^{\circ} \mathrm{C}$ was due to the dehydration/ther- mal transformation of the surface organic functionalities attached via silanol groups [39]. The weight loss between 390 and $500^{\circ} \mathrm{C}$, observed on TGA curves of R380BD, R380MA and R380V samples, originates from thermal decomposition/condensation of silica surface functionalities. Consequently, two peaks on DTG curves (Figure 3b)) are observed for all tested samples. Peak at $205.1^{\circ} \mathrm{C}$ originates from the partial and peak at $449.6{ }^{\circ} \mathrm{C}$ corresponds to the complete thermal degradation of modifying agent.

A difference in the weight loss of modified silica nanoparticles originates from the differences in thermal stability/reactivity of the molecular structure at silica surface. The highest weight loss was observed for the R380BD (32.9\%) which contains long unsaturated aliphatic chain from linseed oil methyl ester, and structure highly sensitive to thermal treatment.

The TGA profile in the range $200-500^{\circ} \mathrm{C}$ is fairly similar for modified silica indicating that weight loss is of low dependence on molecular structure and their thermal degradation process. However, in the range $500-800^{\circ} \mathrm{C}$ appropriate influences of structural differences could be observed, mostly arising from the chain length of linseed oil fatty acid and less from structural diversity of methacryloxy and vinyl structure. Degradation/reactivity of unsaturated aliphatic chain is best understood on the basis of the easily abstractable hydrogens present in trienoate structure, resulting in allyl radicals formation, capable for reactivity transfer and formation of condensed structure. Thermal dehydration/transformation at lower temperatures caused formation of
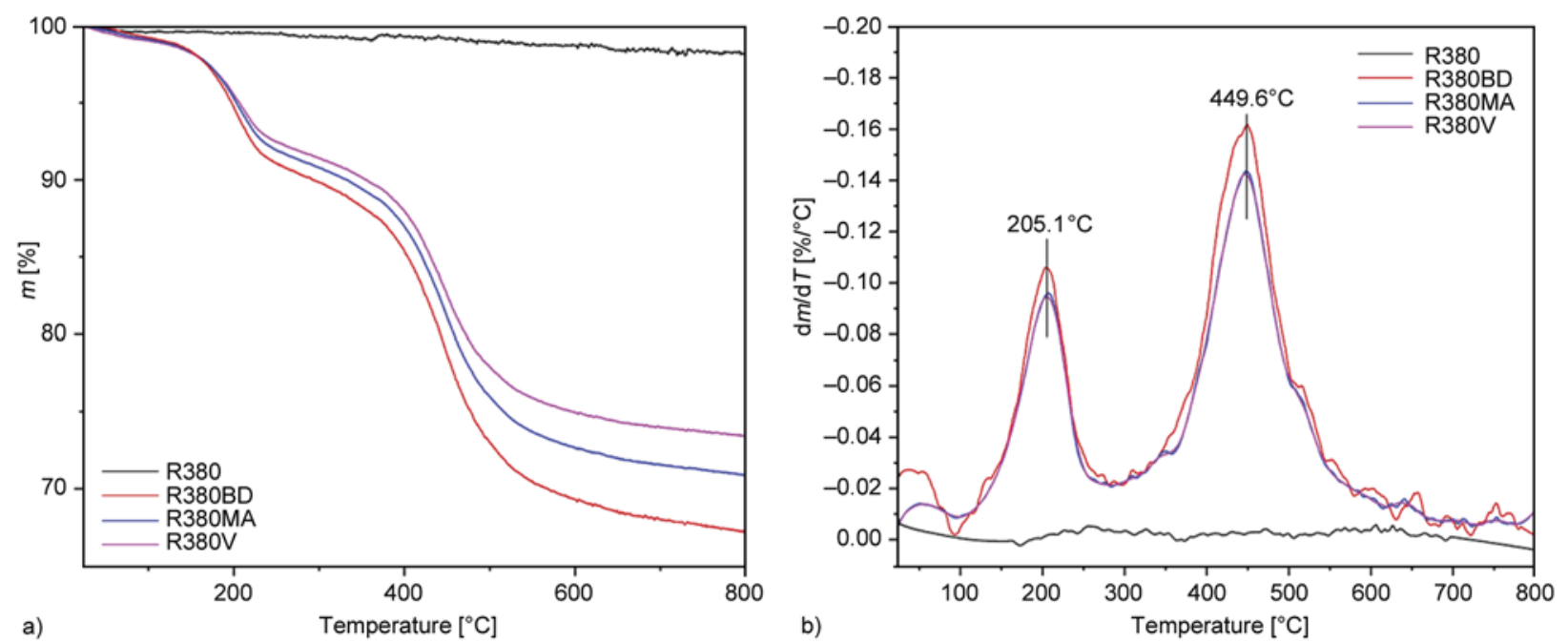

b)

Figure 3. TGA (a) and DTG (b) curves of unmodified Aerosil ${ }^{\circledR} 380$ silica nanoparticles (R380) and modified nanosilica R380BD, R380MA and R380V 
stable condensed surface structures which thermally decompose at higher temperatures. On the other hand, the R380MA has a greater weight loss of $29.9 \%$ than R380V sample, $26.6 \%$, due to the obvious difference in structure of attached fragment at silica surface.

\subsection{NMR characterization of $U P e N$ resin}

Results of NMR analysis confirm successful synthesis of UPe1 and UPe2 resins, and together with results of $M_{\mathrm{n}}$ calculation (Table 2), indicate that unsaturated polyester resin contains mostly fumaric moiety in polymeric chain, which is necessary prerequisite to achieve high cross-linking reactivity during molding/specimen formation.

Results of ${ }^{1} \mathrm{H}$ and ${ }^{13} \mathrm{C}$ NMR analysis (Figure 4) of UPe 1 are as follow:

${ }^{1} \mathrm{H}$ NMR $\left(\mathrm{CDCl}_{3}\right): 1.23-1.51\left(m, 6 \mathrm{H}, 2 \times \underline{\mathrm{C}}_{3}\right)$, 4.20-4.58 ( $\left.m, 6 \mathrm{H}, 2 \times \mathrm{C}_{2} \mathrm{C} \underline{\mathrm{H}}-\right)$ ) 4.25-4.70 ( $m, 4 \mathrm{H}$, $\left.-\mathrm{O}-\mathrm{C}_{2}{ }_{2} \underline{\mathrm{H}}_{2}-\mathrm{O}-\right), 5.21-5.79\left(m, 2 \mathrm{H}, \mathrm{PhCH}=\mathrm{C}_{2}\right.$, styrene moiety), 6.65-6.79 ( $m, 1 \mathrm{H}, \mathrm{PhC} \underline{\mathrm{H}}=\mathrm{CH}_{2}$, styrene moiety), 6.86-6.96 ( $\mathrm{m}, 2 \mathrm{H}$, fumaric moiety), $7.43\left(s, 4 \mathrm{H}, \mathrm{H}_{\mathrm{Ph}}\right.$, styrene moiety), $8.05(s, 4 \mathrm{H}$, $\mathrm{H}_{\mathrm{Ph}}$-terephthaloyl moiety);

${ }^{13} \mathrm{C} \mathrm{NMR}\left(\mathrm{CDCl}_{3}\right): 16.22$ and $19.08\left(2 \times \mathrm{C}_{3}\right), 62.7$, 66.70-69.21, 70.19-70.30, 76.40-77.63 ( $\mathrm{CH}_{2}$ carbons in PG moiety), $113.70\left(4 \times \mathrm{C}_{\mathrm{Ph}}\right.$ in styrene moiety), $126.12-128.43\left(4 \times \mathrm{C}_{\mathrm{Ph}}\right), 134.00(\mathrm{O}=\mathrm{C}-\mathrm{H} \underline{\mathrm{C}}=\underline{\mathrm{C}} \mathrm{H}-\mathrm{C}=\mathrm{O})$, $133.57(2 \times \mathrm{Ph}(\underline{\mathrm{C}})-\mathrm{COO}), \quad 164.08$ and 164.39 $(\mathrm{O}=\underline{\mathrm{C}}-\mathrm{HC}=\mathrm{CH}-\underline{\mathrm{C}}=\mathrm{O}), \quad 164.99$ and 165.28 $(2 \times \mathrm{Ph} \underline{\mathrm{COO}})$. Similar results were found for UPe2 resin.

From the ${ }^{1} \mathrm{H}$ and ${ }^{13} \mathrm{C}$ NMR spectra of the synthesized UPeN resins it can be concluded that the PET glycolysis method has no effect on polycondensation reaction with maleic anhydride, and dominant products were glycol esters of terephthalic acid: bis(2hydroxylpropyl) terephthalate, (2-hydroxyethyl)(2hydroxypropyl) terephthalate and glycols. From the technical-economical aspect of UPes synthesis based on waste PET/PG glycolysis product, the classical method was selected as better alternative for the industrial level of synthesis due to the technological simplicity of synthesis method, in case when the high mechanical properties are not crucial for the application.

\subsection{The $A V, H V, M_{\mathrm{n}}$, iodine value, viscosity, gel time and maximum curing temperature of the synthesized UPeN and UPe2/R(c) nanocomposites}

The products obtained by waste PET glycolysis were used for synthesis of UPes. Zahedi et al. [40] investigated effects of the reaction time, volume of glycol and catalyst contents on the yield of the glycolysis products and after obtaining a suitable glycolysates, the polyesterification of obtained intermediary products and MA was studied. Also, authors determined the optimal reaction time and temperature for the polyesterification of PET glycolizate with MA.

The $A V, H V, M_{\mathrm{n}}$, iodine value and viscosity of UPeN are given in Table 2. From these results it could be observed that synthesized UPeN have similar viscosity, $A V, H V, M_{\mathrm{n}}$, and iodine value and different glycolysis products showed no significant effect on these properties of the obtained resins. Generally, the UPe2, based on the glycolized product obtained by EG azeotropic removal method (2.1.2. b)) contributed to the higher $A V$ and $H V$, while opposite is true for $M_{\mathrm{n}}$, iodine value and viscosity of the obtained products.

The gel time values of UPeN and UPe2/R(c) nanocomposites, determined from the cure exotherm, are given in Table 3 .

The results from Table 3 indicate that presence of $\mathrm{SiO}_{2}$ nanoparticles had different influence on the gel time and the maximum curing temperature $\left(T_{\max }\right)$ of

Table 3. The gel time and maximum curing temperature $\left(T_{\max }\right)$ of the synthesized UPeN and UPe2/R(c) nanocomposites

\begin{tabular}{|l|c|c|}
\hline \multicolumn{1}{|c|}{ Sample } & $\begin{array}{c}\text { Gel time } \\
{[\mathbf{m i n}]}\end{array}$ & $\begin{array}{c}\boldsymbol{T}_{\max } \\
\left.{ }^{\circ} \mathbf{C}\right]\end{array}$ \\
\hline $\mathrm{UPe} 1$ & 19.20 & 145.7 \\
\hline $\mathrm{UPe} 2$ & 14.50 & 172.9 \\
\hline $\mathrm{UPe} 2 / \mathrm{R} 380 \mathrm{BD}(\mathrm{c})$ & 20.00 & 112.9 \\
\hline $\mathrm{UPe} 2 / \mathrm{R} 380 \mathrm{MA}(\mathrm{c})$ & 15.75 & 110.3 \\
\hline $\mathrm{UPe} 2 / \mathrm{R} 380 \mathrm{~V}(\mathrm{c})$ & 9.50 & 127.7 \\
\hline
\end{tabular}

Table 2. The $A V, H V, M_{\mathrm{n}}$, iodine value and viscosity of the synthesized UPeN

\begin{tabular}{|c|c|c|c|c|c|}
\hline Sample & $\begin{array}{c}\boldsymbol{A} \boldsymbol{V} \\
{[\mathbf{m g ~ K O H} / \mathbf{g}]}\end{array}$ & $\begin{array}{c}\boldsymbol{H} \boldsymbol{V} \\
{[\mathbf{m g ~ K O H} / \mathbf{g}]}\end{array}$ & $\begin{array}{c}\boldsymbol{M}_{\mathbf{n}}{ }^{*} \\
{[\mathbf{g} / \mathbf{m o l}]}\end{array}$ & Iodine value & $\begin{array}{c}\text { Viscosity } \\
{[\mathbf{s}]}\end{array}$ \\
\hline $\mathrm{UPe} 1$ & 13.0 & 29.6 & 2634 & 47 & 105 \\
\hline $\mathrm{UPe} 2$ & 13.4 & 30.7 & 2544 & 51 & 90 \\
\hline
\end{tabular}

${ }^{*} M_{\mathrm{n}}$ values were calculated according to the Equation (1). 


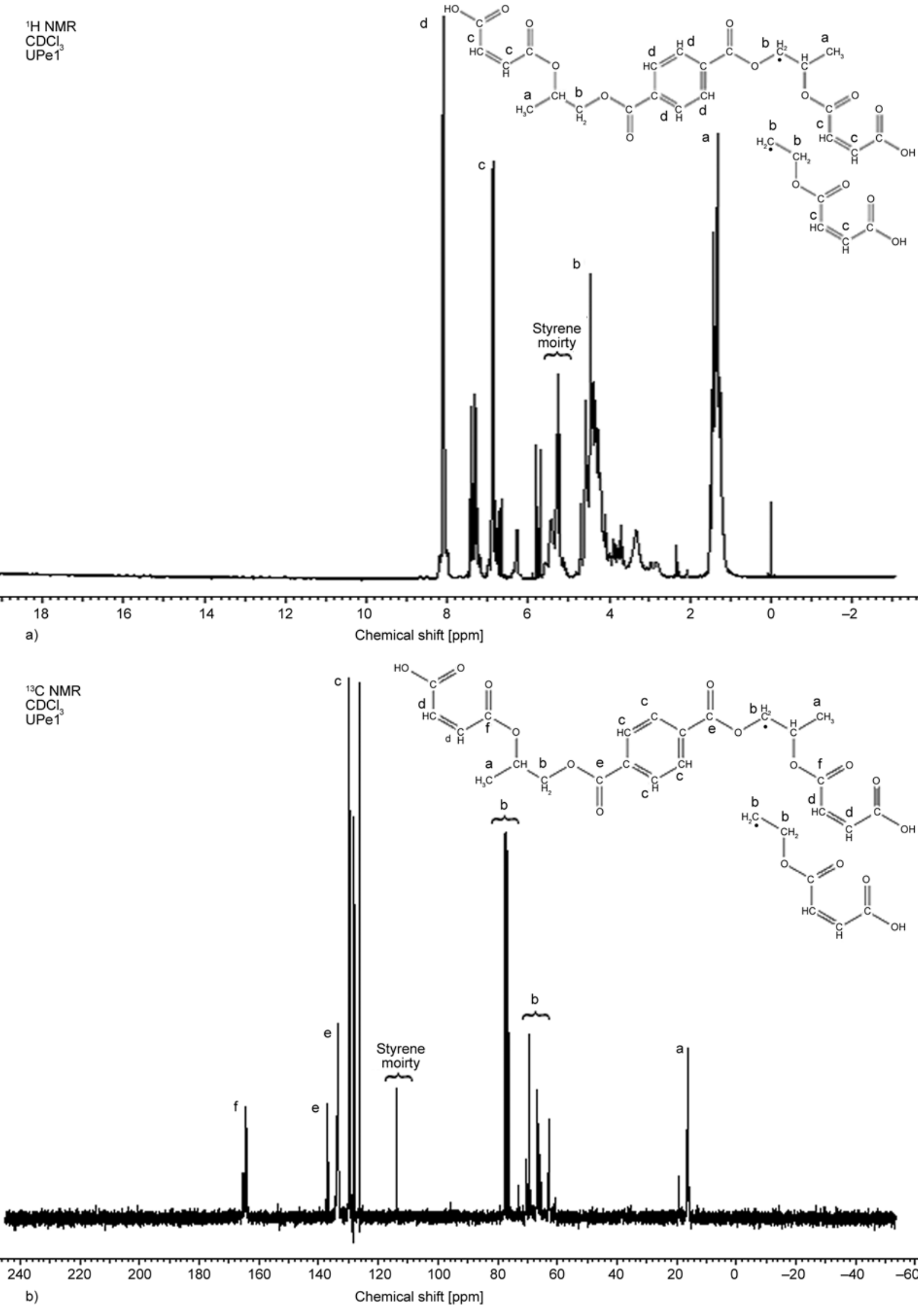

Figure 4. ${ }^{1} \mathrm{H}$ NMR (a) and ${ }^{13} \mathrm{C}$ NMR (b) spectra of UPe1 obtained according to method 2.1.4. a) 
nanocomposite, depending on the type of silica modification. The shorter gel time of UPe2 in comparison to UPe1, $14.50 \mathrm{~min}$ versus $19.20 \mathrm{~min}$, and higher maximum curing temperature, $172.9^{\circ} \mathrm{C}$ versus $145.7^{\circ} \mathrm{C}$, indicate higher reactivity of UPe2 resin. The gel time of UPe2/R380BD(c) was increased slightly, 14.50 to $20.00 \mathrm{~min}$, compared to the UPe2, while $T_{\max }$ was decreased from $172.9^{\circ} \mathrm{C}$, for UPe2, to $112.9^{\circ} \mathrm{C}$ for UPe2/R380BD(c). Silica surface modification with TMSPM and TMEVS caused reduction in the $T_{\max }$ from 172.9 to $110.3^{\circ} \mathrm{C}$ and $127.7^{\circ} \mathrm{C}$, respectively, while the gel time was shorter than for pure UPe2. Gel time was slightly higher for UPe2/ R380MA(c), $15.75 \mathrm{~min}$, and significantly lower value was found for UPe2/R380V(c), $9.50 \mathrm{~min}$.

Incorporation of modified silica nanoparticles in initial UPe polymer matrix influenced cross-linking reaction due to the appropriate contribution of physical interactions and covalent bonding to reactivity/ energetic effect of the curing system. Intermolecular interactions between present functionalities at nanofiller surface and polymeric chain segment prevent, to some extent, favorable approach of vinyl moieties (propagation reaction), causing in that way decrease of $T_{\max }$. Higher reactivity, i.e. mobility of polymeric chain segments in pure UPe, contributes to higher $T_{\max }$, while for UPe2 higher $T_{\max }$ is also affected by better system compatibility. The long unsaturated chain of methyl esters of linseed oil fatty acid in the APTMS-BD structure provides steric hindrance of reactive vinyl group due to high flexibility, in relation to TMSPM and TMEVS modifiers, causing longer reaction period to reach $T_{\max }$. APTMSBD molecules can be randomly oriented and could therefore obscure the reactive sites, and accordingly require a longer gel time to increase the viscosity of the nanocomposites during cross-linking. TMEVS modifier has shortest alkyl chains with the most reactive vinyl group of limited flexibility, which provides the highest reactivity of UPe2/R380V(c) sample, i.e. the shortest gel time was obtained. Appropriate steric repulsion of methyl group present in the TMSPM causes lower accessibility of reacting species to exert reaction with double bond.

\subsection{TEM analysis of UPe2/R(c) nanocomposite materials}

Examination of the influence of the silane coupling agent on the silica dispersion in the UPe matrix of the cured UPe2/R(c) nanocomposites was per-

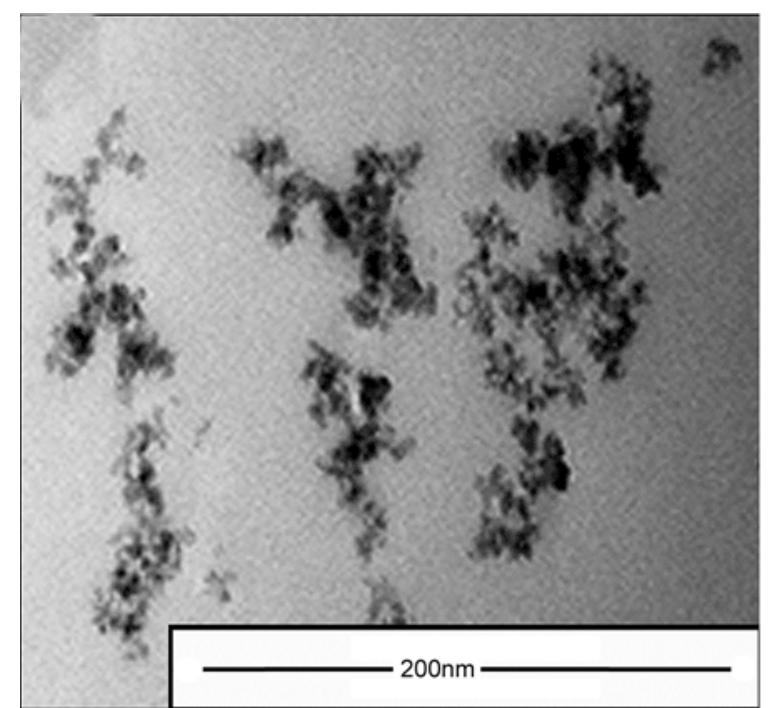

a)

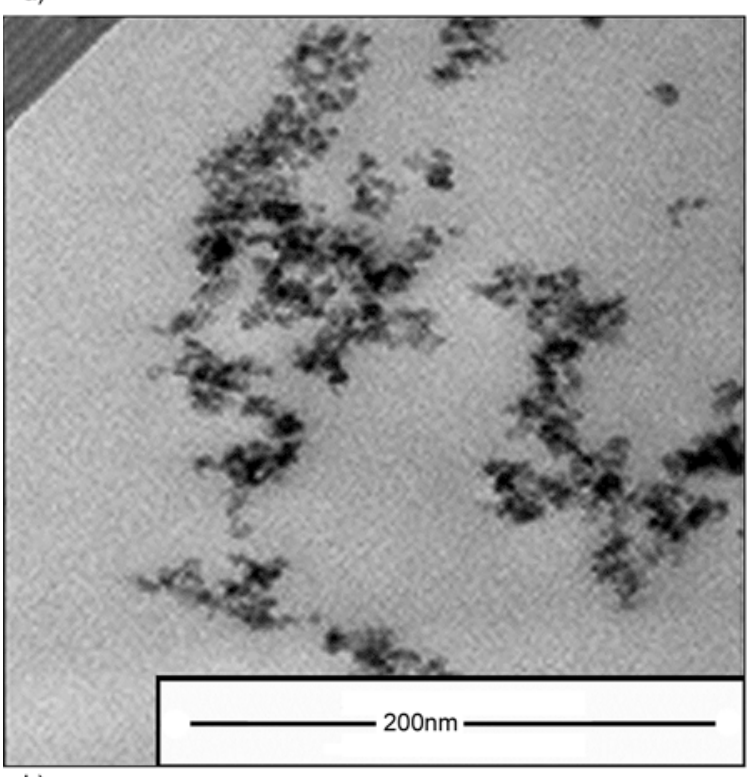

b)

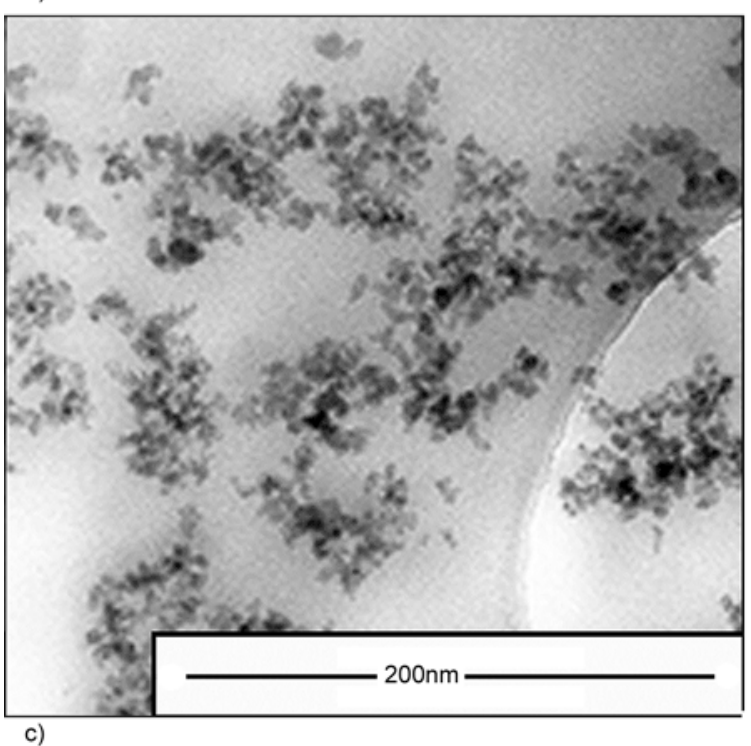

Figure 5. TEM micrographs of (a) UPe2/R380BD(c),

(b) UPe2/ R380MA(c) and

(c) UPe2/R380V(c) nanocomposites 
formed by TEM technique. Figure 5 shows TEM micrographs of UPe2/R380BD(c), UPe2/R380MA(c) and $\mathrm{UPe} 2 / \mathrm{R} 380 \mathrm{~V}(\mathrm{c})$ nanocomposites. From the TEM micrographs of all samples it can be observed that the spherical primary particles of silica nanofiller are to some extent aggregated depending on the properties of silica surface. The primary particles formed irregular chains-like structure with more intensive domain of aggregated nanofiller in UPe2/ R380BD(c) nanocomposite (Figure 5a), less in UPe2/ R380MA(c) (Figure 5b), and the best dispersion was found for UPe2/R380V(c) nanocomposite (Figure 5c)).

The TEM analysis of samples UPe2/R380BD(c) and UPe2/R380MA(c) (Figure 5a and 5b) shows somewhat lower uniformity of the formed aggregates due to the balanced intermolecular interactions between the nanofiller and the nanofiller/cross-linked polymer. In TEM micrograph of UPe2/R380BD(c) an irregular imperfect three-dimensional network of randomly distributed aggregates of modified silica in the polymer matrix was observed. The presence of long linseed oil fatty acid residue on the silica surface led to weakening of the interfacial interaction, due to the lower physical interaction of unsaturated acid residue/UPe matrix. In a similar study, Ou et al. [41] studied effects of alkylation of silica on interfacial interaction, determination, vulcanization swelling procedure, and tensile retraction of modified silica reinforcement of natural, styrenebutadiene and acrylonitrile-butadiene rubber. They have found that the type of the activities of the silica surfaces, methyl, especially hexadecyl alcohol, has influence on the relaxation process weakening interfacial interaction. Analogously, besides to the presence of reactive vinyl groups, the long unsaturated fatty acid chain created spatial barrier between primary spherical nanoparticles and polymeric chain, and the consequence of that was the lowest uniformity of UPe2/R380BD(c). The aggregates found in $\mathrm{UPe} 2 / \mathrm{R} 380 \mathrm{BD}(\mathrm{c})$ sample are the largest, indicating that the highest extent of cohesive interaction between nanofiller exists. The TEM analysis of sample UPe2/R380MA(c) showed similar phase dispersion in the cross-linked polymer/nanofiller as in UPe2/ $\mathrm{R} 380 \mathrm{BD}(\mathrm{c})$. It was caused by moderate repulsive steric interaction of methyl group present in methacryloxy fragment at silica surface. The aggregates observed in sample UPe2/R8380V(c) (Figure 5c) are present in the smallest amount, showing good dispersion of nanoparticles in polymer matrix when TMEVS was used as a modifying agent. Intensive $\pi, \pi$-stacking and different intermolecular interactions at the nanofiller/cross-linked polymeric network interface between terephthaloyl moieties contributed to the better distribution and higher uniformity of the nanofiller (Figure 1). The vinyl group present on silica surface caused the lowest extent of steric interference and the highest reactivity, which provided the highest level of dispersibility. Similar morphological properties were found for other $\mathrm{UPeN} / \mathrm{R}(\mathrm{n})$ nanocomposites.

\subsection{Mechanical testing of UPeN based nanocomposites}

With the aim to investigate influence of different modification type and content of incorporated silica nanoparticles on the mechanical properties of the synthesized nanocomposites based on UPe, the mechanical testing has been done. The stress-strain curves of the examined cured UPeN and UPeN/R380BD(n) samples are shown in Figure 6, and the values of stress at break $\left(\sigma_{\mathrm{b}}\right)$, elongation at break $\left(\varepsilon_{\mathrm{b}}\right)$, and tensile modulus $(E)$ are given in Table 4.

Differences in $\sigma_{\mathrm{b}}$ and $\varepsilon_{\mathrm{b}}$ value of pure UPeN are mainly caused by properties of the products of PET glycolysis. Higher stress and elongation at break, found for UPe2, is due to the higher structural homogeneity of cross-linked polymeric network, in comparison to UPe1. PET glycolysis product, obtained by method 2.1.2. b) mainly contains bis(2hydroxypropyl) terephthalate, while the product of glycolysis used in UPe1 synthesis also includes asymmetrical terephthalic ester containing ethylene glycol residue, which contributed to segmental structure of polyester chain. Also, difference in the transfer of reactivity, i.e. rate of propagation reaction during cross-linking, could be of appropriate significance.

Results of mechanical testing indicate that $\sigma_{\mathrm{b}}$ and $E$ increase with increasing silica content in nanocomposite samples, while $\varepsilon_{\mathrm{b}}$ is slightly higher for nanocomposite samples than for the pure UPeN. The presence of long BD chain in APTMS-BD on the silica surface, which represents the soft-elastic segment in nanofiller/cross-linked polymer, contributes to higher $\varepsilon_{\mathrm{b}}$ values than for pure UPeN. Also, in accordance with its structure, APTMS-BD can have a plasticizing effect in cross-linking process. With increasing silica content in UPeN/R380BD $(a-c)$ 

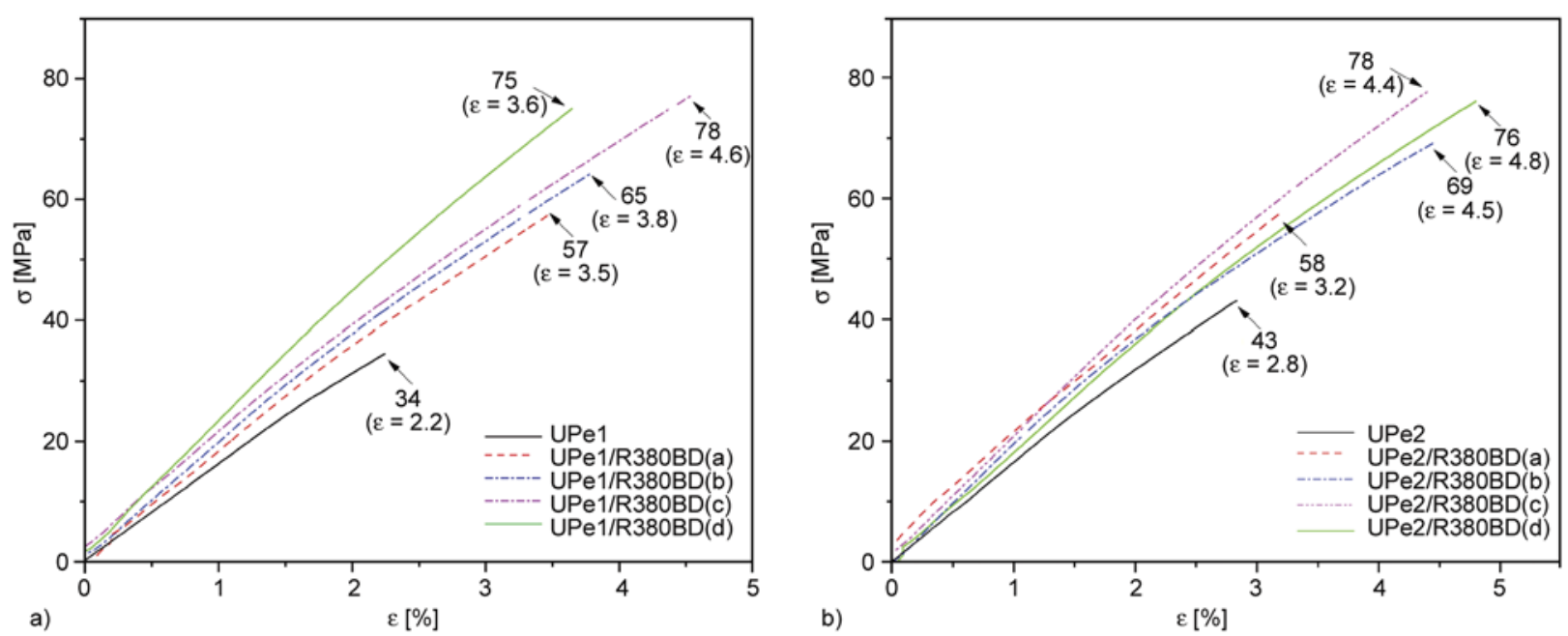

Figure 6. The stress-strain curves of the cured (a) UPe1 and UPe1/R380BD(n) and (b) UPe2 and UPe2/R380BD(n) nanocomposites

Table 4. Stress at break $\left(\sigma_{\mathrm{b}}\right)$, elongation at break $\left(\varepsilon_{\mathrm{b}}\right)$ and tensile modulus $(E)$ of cured $\operatorname{UPe} 1 / \operatorname{R} 380 \mathrm{BD}(\mathrm{n})$ and $\mathrm{UPe} 2 /$ $\mathrm{R} 380 \mathrm{BD}(\mathrm{n})$ nanocomposites

\begin{tabular}{|l|c|c|c||l|l|l|c|}
\hline \multicolumn{1}{|c|}{ Sample } & $\begin{array}{c}\boldsymbol{\sigma}_{\mathbf{b}} \\
{[\mathbf{M P a}]}\end{array}$ & $\begin{array}{c}\boldsymbol{\varepsilon}_{\mathbf{b}} \\
{[\mathbf{\%}]}\end{array}$ & $\begin{array}{c}\boldsymbol{E} \\
{[\mathbf{G P a}]}\end{array}$ & \multicolumn{1}{|c|}{ Sample } & $\begin{array}{c}\boldsymbol{\sigma}_{\mathbf{b}} \\
{[\mathbf{M P a}]}\end{array}$ & $\begin{array}{c}\boldsymbol{\varepsilon}_{\mathbf{b}} \\
{[\mathbf{\%}]}\end{array}$ & $\begin{array}{c}\boldsymbol{E} \\
{[\mathbf{G P a}]}\end{array}$ \\
\hline UPe1 & $34 \pm 1.0$ & 2.2 & 1.5 & UPe2 & $43 \pm 1.4$ & 2.8 & 1.8 \\
\hline UPe1/R380BD(a) & $57 \pm 1.7$ & 3.5 & 2.2 & UPe2/R380BD(a) & $58 \pm 1.3$ & 3.2 & 2.3 \\
\hline UPe1/R380BD(b) & $65 \pm 1.3$ & 3.8 & 2.7 & UPe2/R380BD(b) & $69 \pm 1.9$ & 4.5 & 2.4 \\
\hline UPe1/R380BD(c) & $78 \pm 1.9$ & 4.6 & 2.9 & UPe2/R380BD(c) & $78 \pm 1.7$ & 4.4 & 2.2 \\
\hline UPe1/R380BD(d) & $75 \pm 1.7$ & 3.6 & 1.6 & UPe2/R380BD(d) & $76 \pm 1.6$ & 4.8 & 1.9 \\
\hline
\end{tabular}

nanocomposite samples, prevalence of soft-elastic segments increases, as well as elongation at break. Stress at break increases with increasing silica content, and the highest $\sigma_{\mathrm{b}}$ value have the UPeN/ $\mathrm{R} 380 \mathrm{BD}(\mathrm{c})$ samples with aggregates formed of spherical APTMS-BD modified silica nanoparticles.

Figure 7 shows stress-strain curves of the cured UPeN and UPeN/R380MA(n) nanocomposites and

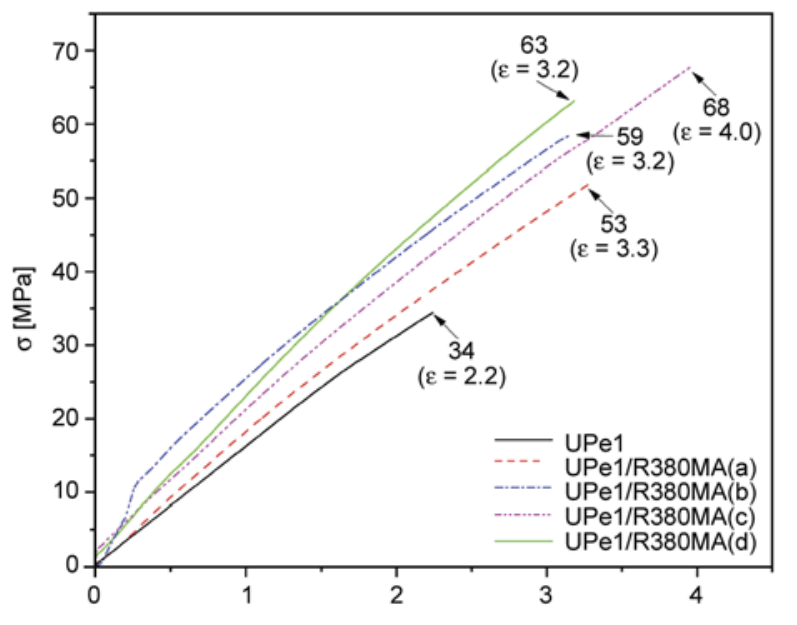

a)

$\varepsilon[\%]$ appropriate values of stress at break, elongation at break and tensile modulus are given in Table 5 .

The results of mechanical testing of UPeN/ R380MA(n) nanocomposites based on UPeN and TMSPM modified silica show similar trend as UPeN/ R380BD(n) samples. With increasing silica content in $\mathrm{UPeN} / \mathrm{R} 380 \mathrm{MA}(\mathrm{a}-\mathrm{c})$ nanocomposites, increase of elongation at break and stress at break was observed.

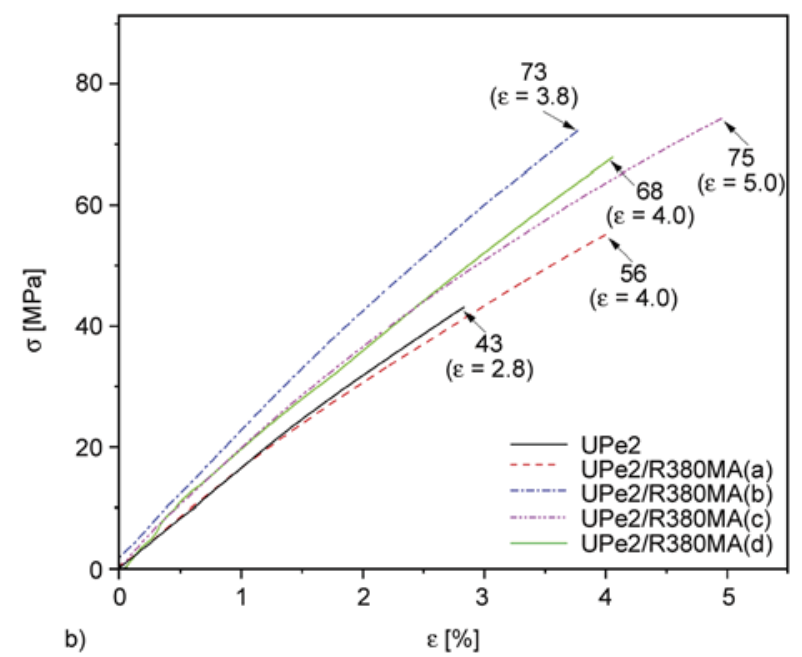

Figure 7. The stress-strain curves of the cured (a) UPe1 and UPe1/R380MA(n) and (b) UPe2 and UPe2/R380MA(n) nanocomposites 
Table 5. Stress at break $\left(\sigma_{\mathrm{b}}\right)$, elongation at break $\left(\varepsilon_{\mathrm{b}}\right)$ and tensile modulus $(E)$ of cured UPe1/R380MA(n) and UPe $2 /$ R380MA(n) nanocomposites

\begin{tabular}{|l|c|c|c||l|c|c|c|}
\hline \multicolumn{1}{|c|}{ Sample } & $\begin{array}{c}\boldsymbol{\sigma}_{\mathbf{b}} \\
{[\mathbf{M P a}]}\end{array}$ & $\begin{array}{c}\boldsymbol{\varepsilon}_{\mathbf{b}} \\
{[\mathbf{\%}]}\end{array}$ & $\begin{array}{c}\boldsymbol{E} \\
{[\mathbf{G P a}]}\end{array}$ & Sample & $\begin{array}{c}\boldsymbol{\sigma}_{\mathbf{b}} \\
{[\mathbf{M P a}]}\end{array}$ & $\begin{array}{c}\boldsymbol{\varepsilon}_{\mathbf{b}} \\
{[\mathbf{\%}]}\end{array}$ & $\begin{array}{c}\boldsymbol{E} \\
{[\mathbf{G P a}]}\end{array}$ \\
\hline UPe1/R380MA(a) & $53 \pm 1.3$ & 3.3 & 1.8 & UPe2/R380MA(a) & $56 \pm 1.3$ & 4.0 & 1.9 \\
\hline UPe1/R380MA(b) & $59 \pm 1.2$ & 3.2 & 2.0 & UPe2/R380MA(b) & $73 \pm 1.6$ & 3.8 & 2.1 \\
\hline UPe1/R380MA(c) & $68 \pm 1.7$ & 4.0 & 1.9 & UPe2/R380MA(c) & $75 \pm 2.0$ & 5.0 & 2.0 \\
\hline UPe1/R380MA(d) & $63 \pm 1.7$ & 3.2 & 2.4 & UPe2/R380MA(d) & $68 \pm 1.5$ & 4.0 & 2.0 \\
\hline
\end{tabular}

The highest stress at break was observed for UPeN/ R380MA(c). By incorporation of more than $1.0 \mathrm{wt} \%$ of silica nanoparticles in cross-linked polymer/nanofiller, elongation at break and stress at break decrease due to the deterioration of the homogeneity of nanocomposite with the increase of silica addition, i.e. phase mixing/dispersing of nanofiller is not satisfactory. Guo et al. [42] investigated mechanical properties of polymeric nanocomposites based on TMSPM surface functionalized alumina nanoparticle and vinyl ester resin. They have found that modified alumina nanoparticles formed particle/matrix interfacial bonding, which allowed larger local plastic deformation in the matrix and resulted in significant increase in both modulus and strength, from $2.75 \mathrm{GPa}$ (pure resin) to $3.25 \mathrm{GPa}$ and $52.4 \mathrm{MPa}$ to $63.3 \mathrm{MPa}$ for $1 \mathrm{wt} \%$ modified alumina nanoparticles, respectively [42].

Figure 8 shows stress-strain curves of the cured UPe1 and UPe1/R380V(n) nanocomposites and determined values of stress at break, elongation at break and tensile modulus are given in Table 6.

In the case of UPe1/R380V(n) composite materials, the highest values of elongation at break and stress at break with regard to the pure cross-linked UPe1 are recorded. These results are associated with

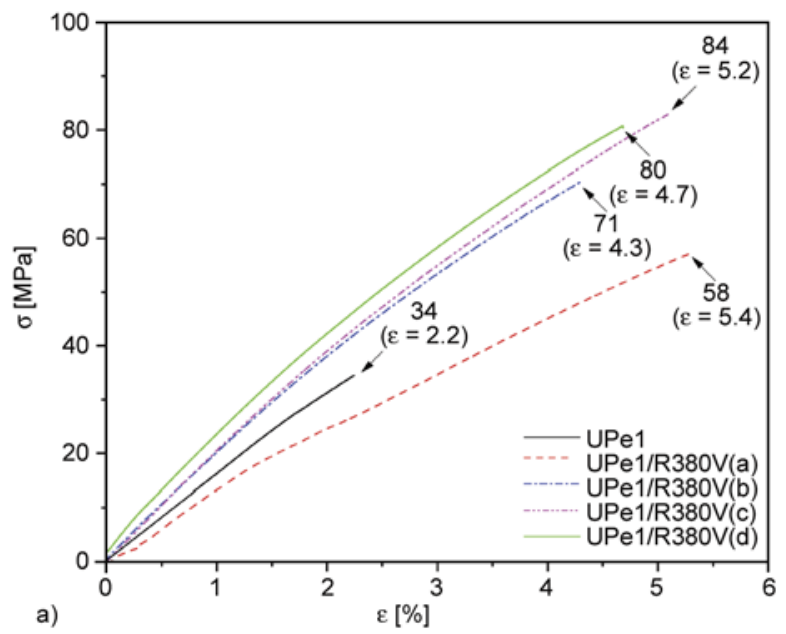

TMEVS configuration. The side chains with 1,2dimethoxyethyl groups are short and oriented so that they cannot cause steric hindrance and hide the active sites on the modified silica surface. Kanimozhi et al. [43] proved vinyl silane functionalized rice husk ash reinforcing effect on unsaturated polyester nanocomposites. They confirmed that the reinforced composites exhibited higher thermal and mechanical properties than neat UPe. Modifiers, APTMS-BD and TMSPM, can occupy twisted conformation, due to the flexibility of unsaturated fatty acid residue, and due to the interaction with surface functional groups by forming closed structure which prevent availability of vinyl active sites (Figure 1). In order to determine the effect of the organic structure of the surface coupling agent on the flexural and impact strength of the cured UPeN/R(c) composites, the flexural strength and Charpy impact testing was performed. Determined values of impact $\left(\sigma_{\mathfrak{i}}\right)$ and flexural strength $\left(\sigma_{\mathrm{f}}\right)$ are given in Table 7.

Obtained results indicate that impact and flexural properties increase with $1.0 \mathrm{wt} \%$ filler loading for both UPeN based nanocomposites [43]. The impact strength increase from 109 to $131 \%$ and from 108 to $113 \%$ for UPe1 and UPe2 based nanocomposites, while the flexural strength increase from 108 to $156 \%$

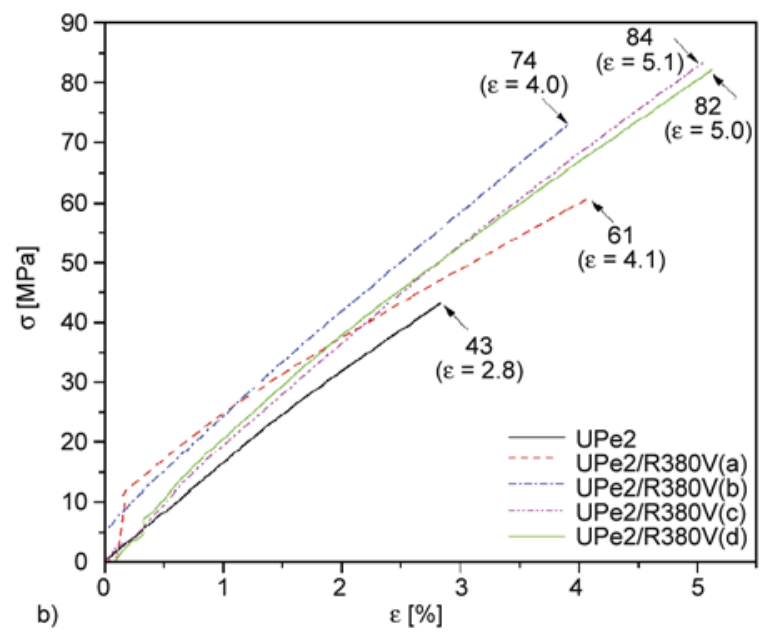

Figure 8. The stress-strain curves of the cured (a) UPe1 and UPe1/R380V(n) and (b) UPe2 and UPe2/R380V(n) 
Table 6. Stress at break $\left(\sigma_{\mathrm{b}}\right)$, elongation at break $\left(\varepsilon_{\mathrm{b}}\right)$ and tensile modulus $(E)$ of cured UPe1/R380V(n) and UPe2/R380V(n) nanocomposites

\begin{tabular}{|l|c|c|c||l|l|c|c|}
\hline \multicolumn{1}{|c|}{ Sample } & $\begin{array}{c}\boldsymbol{\sigma}_{\mathbf{b}} \\
{[\mathbf{M P a}]}\end{array}$ & $\begin{array}{c}\boldsymbol{\varepsilon}_{\mathbf{b}} \\
{[\mathbf{\%}]}\end{array}$ & $\begin{array}{c}\boldsymbol{E} \\
{[\mathbf{G P a}]}\end{array}$ & Sample & $\begin{array}{c}\boldsymbol{\sigma}_{\mathbf{b}} \\
{[\mathbf{M P a}]}\end{array}$ & $\begin{array}{c}\boldsymbol{\varepsilon}_{\mathbf{b}} \\
{[\mathbf{\%}]}\end{array}$ & $\begin{array}{c}\boldsymbol{E} \\
{[\mathbf{G P a}]}\end{array}$ \\
\hline UPe1/R380V(a) & $58 \pm 1.3$ & 5.4 & 1.7 & UPe2/R380V(a) & $61 \pm 1.4$ & 4.1 & 1.6 \\
\hline UPe1/R380V(b) & $71 \pm 1.5$ & 4.3 & 1.7 & UPe2/R380V(b) & $74 \pm 1.5$ & 4.0 & 1.9 \\
\hline UPe1/R380V(c) & $84 \pm 2.0$ & 5.2 & 1.9 & UPe2/R380V(c) & $84 \pm 1.9$ & 5.1 & 1.8 \\
\hline UPe1/R380V(d) & $80 \pm 1.9$ & 4.7 & 1.6 & UPe2/R380V(d) & $82 \pm 1.9$ & 5.0 & 1.8 \\
\hline
\end{tabular}

Table 7. Values of impact and flexural strength of cured UPeN/R(c

\begin{tabular}{|c|c|c|c|c|c|}
\hline Sample & $\begin{array}{c}\sigma_{\mathbf{i}} \\
{\left[\mathbf{J} \cdot \mathbf{m}^{-1}\right]}\end{array}$ & $\begin{array}{c}\sigma_{\mathrm{f}} \\
{[\mathrm{MPa}]}\end{array}$ & Sample & $\begin{array}{c}\sigma_{\mathbf{i}} \\
{\left[\mathbf{J} \cdot \mathbf{m}^{-1}\right]}\end{array}$ & $\begin{array}{c}\sigma_{\mathrm{f}} \\
{[\mathrm{MPa}]}\end{array}$ \\
\hline UPe1 & $145.6 \pm 4.6$ & $66.7 \pm 1.7$ & UPe2 & $109.2 \pm 3.4$ & $61.7 \pm 1.6$ \\
\hline UPe1/R380BD(c) & $159.2 \pm 4.3$ & $103.9 \pm 3.0$ & UPe2/R380BD(c) & $118.3 \pm 3.2$ & $81.0 \pm 2.4$ \\
\hline UPe1/R380MA(c) & $158.6 \pm 4.6$ & $81.6 \pm 2.3$ & UPe2/R380MA(c) & $113.7 \pm 2.9$ & $68.5 \pm 1.9$ \\
\hline UPe1/R380V(c) & $191.1 \pm 6.1$ & $72.0 \pm 2.3$ & UPe2/R380V(c) & $122.8 \pm 3.4$ & $65.6 \pm 1.6$ \\
\hline
\end{tabular}

and from 106 to $133 \%$ for UPe1 and UPe2 based composites, respectively. Lower values of impact and flexural strength of UPe2 based nanocomposites indicate that those materials absorb lower amount of energy and have brittle transition. Also, the highest values of flexural strength of UPeN/R380BD(c) are due to best interfacial adhesion between filler and polymer matrix and indicate that the plasticizing effect of APTMS-BD moiety. The UPe2/R380MA(c) has higher values of $\sigma_{\mathrm{f}}$ than UPe2/R380V(c) [44]. The influence of $\mathrm{SiO}_{2}$ nanofiller content on the stress at break of UPeN/R is shown in Figure 9.

Obtained results, given in Figure 9, indicate that stress at break of all UPeN/R nanocomposites increased with increasing $\mathrm{R}$ content up to the $1 \mathrm{wt} \%$, and after that it is constant or slightly decreased. Incorporating of more than $2 \mathrm{wt} \%$ of modified silica nanoparticles caused formation of larger aggregates which represent vulnerabilities/weak point in cross-

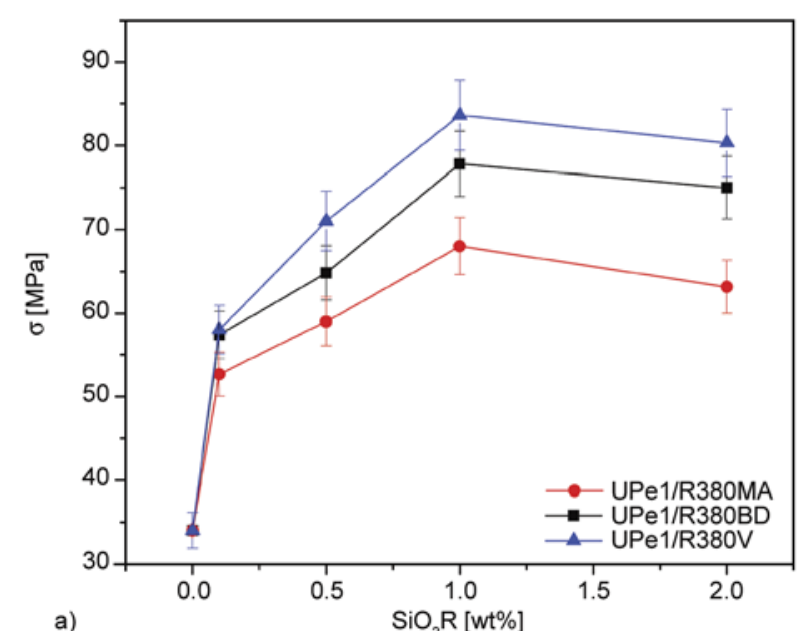

linked polymer-nanofiller composite. The larger diameter of the silica cluster, larger for higher percent of added nanofiller, indicates balanced contribution of both silica/matrix and silica/silica interactions where contribution of later one increases with silica content increase.

It was evident that the content and the type of modification of silica nanoparticles had an appropriate influence on the mechanical properties of the obtained nanocomposites. Modified silica reinforced composites exhibit higher mechanical properties than neat cured UPe matrix due to the hydrophobicity of the silica surface, i.e. improved compatibility with UPe matrix, and thus higher reactivity contributes to higher cross-linking density. The stress at break of UPeN/R (Figure 9) reflects influence of vinyl based $\mathrm{SiO}_{2}$ modification on the nanofiller dispersibility (Figure 5), extent of intermolecular interactions (Figure 1) and steric interference to vinyl group reactiv-

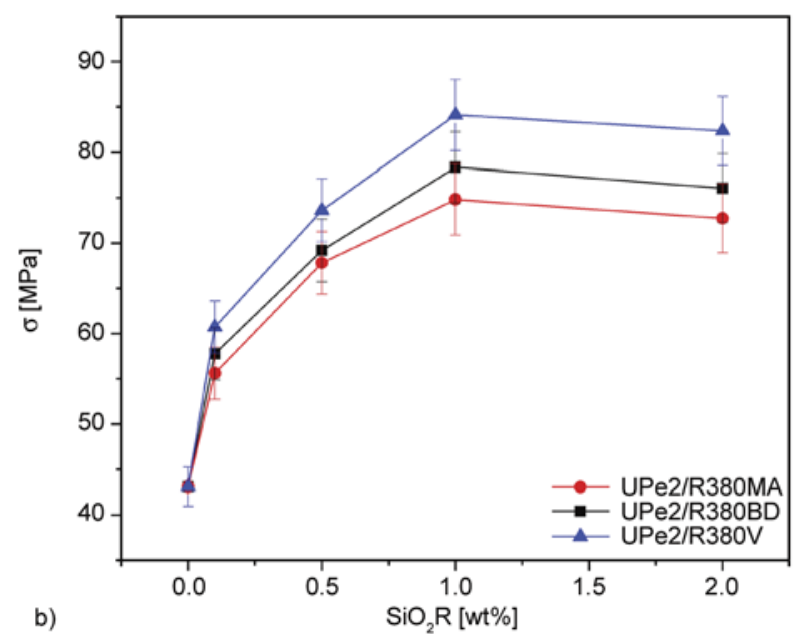

Figure 9. The influence of $\mathrm{SiO}_{2}$ nanofiller content on the stress at break of (a) UPe1/R and (b) UPe2/R materials 
ity. Lower values of stress at break for R380MA and $\mathrm{R} 380 \mathrm{BD}$ are influenced by electronic and steric/conformational effect. The UPeN/R380BD nanocomposites have higher values of $\sigma_{\mathrm{b}}$, compared to UPeN/ R380MA, due to the presence of allylic hydrogen and number of ethylenic in flexible structure more likely to be involved in cross-linking process. Also, structural differences between UPe1 and UPe2 resin, due to the different EG/PG ratio in polyester chain and higher flexibility of PG moiety, influences nanocomposites properties. Extent of the interactions depends on the nature of the functional groups present on the surface of the fumed silica and UPe chain: high intensity $\pi, \pi$-stacking attractive interaction between vinyl and terephthaloyl moieties contribute to effective networking of the obtained system. On the other hand, low intensity non-covalent interactions: London dispersive forces, Van der Waals and different dipolar interactions had a smaller contribution to orderliness and physical cross-linking, influence lower extent on the mechanical properties of the obtained nanocomposites (Figure 1).

\subsection{DMA and DSC analysis of cured UPeN and $\mathrm{UPeN} / \mathrm{R}(\mathrm{n})$ nanocomposites}

Chemical composition and configuration of the synthesized macromolecules, interaction between polymer chains and filler nanoparticles have influence on material crystallinity, phase formation, and dynamicmechanical properties of composite materials.

The temperature dependences of storage modulus $\left(G^{\prime}\right)$, which reflects elastic behavior, loss modulus $\left(G^{\prime \prime}\right)$, which reflects viscous behavior of pure UPeN and $\mathrm{UPeN} / \mathrm{R}(\mathrm{c})$ nanocomposites are given in Fig-

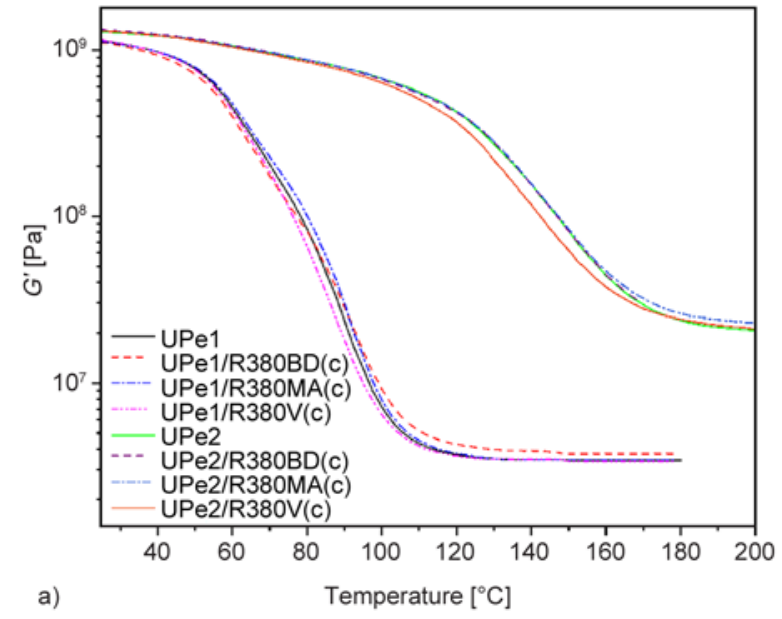

ure 10. Results of the dynamic-mechanical analysis (DMA) of the investigated samples, presented in Figure 10, show that there is no significant difference in $G^{\prime}$ and $G^{\prime \prime}$ values between samples of the same nanocomposite group, indicating that different modification type of applied silica nanoparticles has a minor influence on the dynamic-mechanical properties of the prepared nanocomposites. On the other hand, pure UPe2 and UPe2/R(c) nanocomposites have significantly higher $G^{\prime}$ values than pure UPe1 and $\mathrm{UPe} 1 / \mathrm{R}(\mathrm{c})$ in the whole investigated temperature region, as can also be observed from the values of the storage modulus in the glassy state $\left(G_{\mathrm{GS}}^{\prime}\right)$, at $50^{\circ} \mathrm{C}$, and in the rubbery state $\left(G_{\mathrm{RP}}^{\prime}\right)$ (Table 8$)$. Furthermore, rubbery plateau region of samples prepared with UPe 2 as polymer matrix appears at higher temperatures $\left(T>180^{\circ} \mathrm{C}\right)$ than rubbery plateau region of samples based on UPe1 $\left(T>120^{\circ} \mathrm{C}\right) . G_{\mathrm{RP}}^{\prime}$ values of $\mathrm{UPe} 2 / \mathrm{R}(\mathrm{c})$ are more than one order of magnitude higher than $G_{\mathrm{RP}}^{\prime}$ values of UPe $1 / \mathrm{R}(\mathrm{c})$, indicating large difference in the cross-linking density between these two nanocomposite groups, caused by the presence of different polymer matrix. The same trend was observed for the pure UPe1 and UPe2. Smaller difference between $G^{\prime}$ values in the glassy and rubbery states for pure UPe2 and UPe2/R(c) nanocomposites in comparison to the samples based on UPe1 is also related to the higher cross-linking density of UPe2-based samples [45]. The trend of the $G^{\prime \prime}$ values change for two groups of samples depends on the temperature, i.e. up to the approximately $110^{\circ} \mathrm{C}$ pure $\mathrm{UPe} 1$ and UPe1/R(c) nanocomposites have higher $G^{\prime \prime}$ values than pure UPe2 and UPe2/R(c) nanocomposites. Opposite is true at higher temperatures.

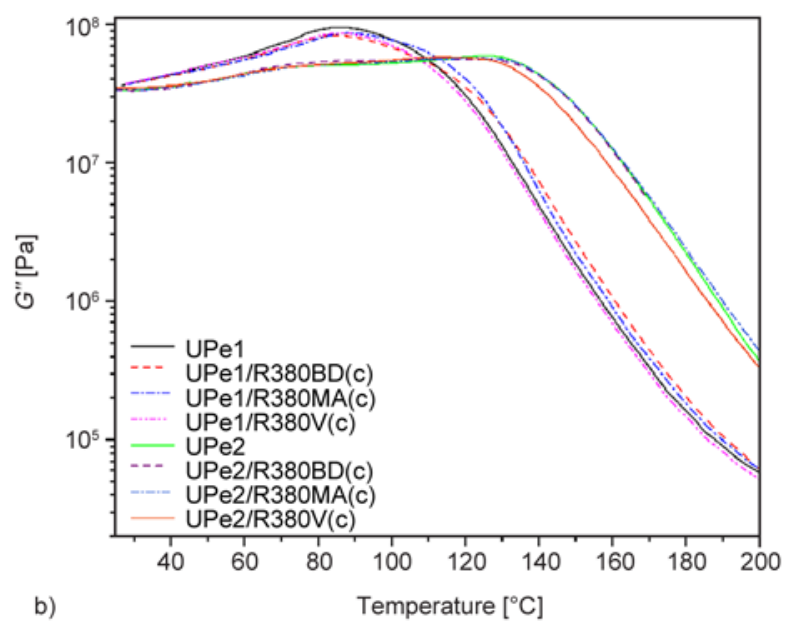

Figure 10. Temperature dependence of (a) storage modulus $\left(G^{\prime}\right)$ and (b) loss modulus $\left(G^{\prime \prime}\right)$ of pure UPeN and UPeN/R(c) nanocomposites 
Table 8. Results of DMA and DSC analysis of the UPeN and UPeN/R(c)

\begin{tabular}{|c|c|c|c|c|c|c|}
\hline Sample & $\begin{array}{c}G_{\mathrm{GS}}^{\prime} \\
{[\mathrm{MPa}]}\end{array}$ & $\begin{array}{c}G_{\mathrm{RP}}^{\prime} \\
{[\mathrm{MPa}]}\end{array}$ & $\begin{array}{c}T_{\mathrm{g}(\tan \delta \text { peak })} \\
{\left[{ }^{\circ} \mathrm{C}\right]}\end{array}$ & $\tan \delta$ height & $\begin{array}{c}T_{\mathrm{g}(\mathrm{DSC})} \\
{\left[{ }^{\circ} \mathrm{C}\right]}\end{array}$ & $\begin{array}{c}v \cdot 10^{3} \\
{\left[\mathrm{~mol} / \mathrm{cm}^{3}\right]}\end{array}$ \\
\hline UPe1 & 780 & 3.4 & 92.4 & 0.96 & 92.0 & 3.4 \\
\hline UPe1/R380BD(c) & 720 & 3.7 & 95.1 & 0.92 & 94.1 & 3.5 \\
\hline UPe1/R380MA(c) & 790 & 3.4 & 93.8 & 0.96 & 93.1 & 3.4 \\
\hline UPe1/R380V(c) & 760 & 3.4 & 91.3 & 0.95 & 90.0 & 3.4 \\
\hline $\mathrm{UPe} 2$ & 1100 & 23.6 & 151.3 & 0.32 & 141.1 & 5.4 \\
\hline UPe2/R380BD(c) & 1200 & 24.0 & 151.3 & 0.32 & 145.2 & 5.4 \\
\hline UPe2/R380MA(c) & 1100 & 26.0 & 151.3 & 0.32 & 146.3 & 5.5 \\
\hline UPe2/R380V(c) & 1100 & 24.0 & 145.0 & 0.31 & 145.2 & 4.3 \\
\hline
\end{tabular}

In the temperature dependence of the mechanical loss factor of pure UPeN and the prepared composites given in Figure 11, only one peak in the range 91.3$95.1^{\circ} \mathrm{C}$ for UPe1 and nanocomposites based on UPe1 and in the range $145.0-151.3^{\circ} \mathrm{C}$ for UPe 2 and nanocomposites based on UPe 2 can be seen. The temperature associated with loss factor peak corresponds to the glass transition temperature $\left(T_{\mathrm{g}}\right)$ of the investigated samples. The $T_{\mathrm{g}}$ values of pure UPeN and prepared nanocomposites determined from the $\tan \delta$ temperature dependence are listed in Table $8 . T_{\mathrm{g}(\tan \delta \text { peak })}$ values of UPe1/R380(c) nanocomposites prepared using R380BD and R380MA nanoparticles are higher than $T_{\mathrm{g}}$ of pure UPe1, which implies that the presence of these surface modified $\mathrm{SiO}_{2}$ nanoparticles restricted molecular mobility of polymer chains at the interface between UPe 1 and nanoparticles, due to the presence of the attractive interactions between nanoparticles and polymer matrix. The opposite was obtained for UPe1/R380V(c) nanocomposite. When UPe 2 was used as polymer matrix, R380BD and R380MA nanoparticles showed no influence on the $T_{\mathrm{g}}$ of UPe2, while $T_{\mathrm{g}}$ of UPe2/R380V(c) nanocom-

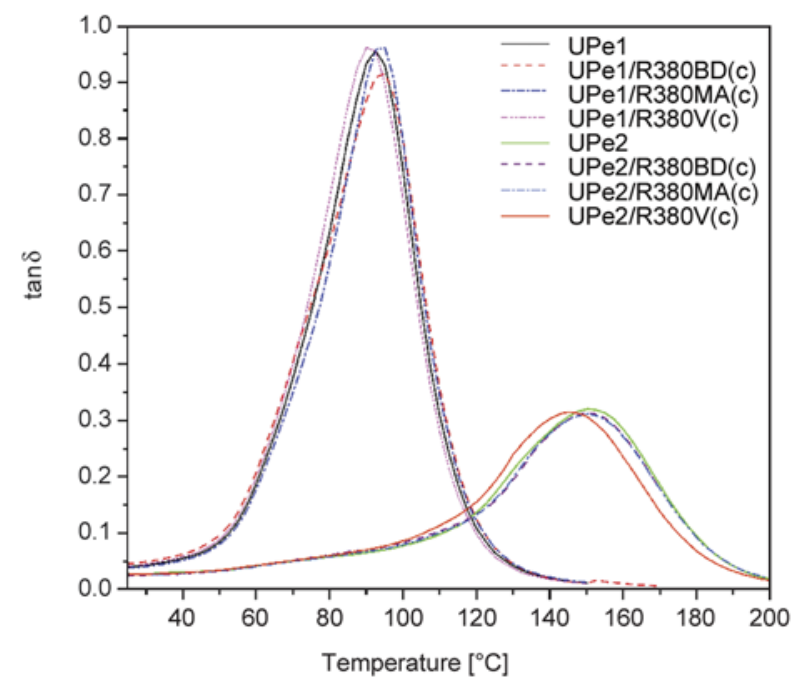

Figure 11. Temperature dependence of $\tan \delta$ of pure UPeN and $\mathrm{UPeN} / \mathrm{R}(\mathrm{c})$ nanocomposites posite was lower than $T_{\mathrm{g}}$ of pure UPe2. Furthermore, $T_{\mathrm{g}}$ of cured UPe1 and UPe1/R(c) samples is lower than $T_{\mathrm{g}}$ of UPe2 and UPe2/R(c), due to the higher cross-linking density of the samples based on UPe2. This is also evidenced by the maximum values of $\tan \delta$ ( $\tan \delta$ height) listed in Table 8 , since it is known that samples with higher $\tan \delta$ values have lower cross-linking density, i.e. higher mobility of the chain segments between cross-links [46]. It is also interesting to notice that $\tan \delta$ peaks of UPe 2 and UPe $2 / R(c)$ nanocomposites are broader than $\tan \delta$ peaks of UPe 1 and UPe1/R(c) samples, indicating higher cross-link non-uniformity, i.e. more heterogeneous polymer network and broad distribution of relaxation times in samples based on UPe2 [47, 48].

Values of the cross-linking density $(v)$ of the prepared samples were calculated from $G_{\mathrm{RP}}^{\prime}$ following the Equation (2):

$\nu=\frac{\left(G_{\mathrm{RP}}^{\prime}\right)}{R T}$

where $R$ is the universal gas constant and $T$ is $T_{\mathrm{g}}+30^{\circ} \mathrm{C}$. Determined values of the cross-linking density of the investigated samples are summarized in Table 8. It can be observed that different modification type of $\mathrm{SiO}_{2}$ had no influence on the crosslinking density of pure UPe1 and UPe1/R(c) nanocomposites. Similar trend was observed for pure UPe 2 and UPe2/R(c) nanocomposites, except for UPe2/R380V(c) which has slightly lower $v$ than pure UPe 2 and other UPe2/R(c) nanocomposites, which is in accordance with determined $T_{\mathrm{g}}$ values and investigated mechanical properties. Obtained DMA results revealed that type of the UPe used as polymer matrix has more pronounced influence on the dynamic-mechanical properties of the investigated nanocomposites has than the type of $\mathrm{SiO}_{2}$ nanoparticles used for modification. Samples based on unsaturated polyester prepared using PET glycolysis product obtained by ethylene glycol azeotropic removal 
method have higher cross-linking density and consequently lower molecular weight between cross-links than samples based on UPe1, synthesized using product obtained by classical method of PET glycolysis.

In order to determine the thermal properties of the cured UPeN and UPeN/R(n) nanocomposites, differential scanning calorimetry was performed, whereby two heating runs, as well as a cooling run between them were recorded. From the results of DSC analysis (Figure 12) similar values of $T_{\mathrm{g}}$ to ones determined by DMA analysis, and no significant differences between $T_{\mathrm{g}}$ of pure cured UPeN and UPeN/R(c) nanocomposites were found. Generally, the $T_{\mathrm{g}}$ values of cured UPe1 and corresponding nanocomposites are in the range $92.0-94.1^{\circ} \mathrm{C}$, and of cured UPe2 and corresponding nanocomposites are in the range $141.1-146.2^{\circ} \mathrm{C}$.

In a similar manner to the present work, nanocomposites based on UPe and fumed silica Aerosil ${ }^{\circledR}$ R812S, R805 and R816, and R200 modified with phenyl terminal group, R200NPh were investigated [15]. Aerosil ${ }^{\circledR} \mathrm{R} 812 \mathrm{~S}, \mathrm{R} 805$, and $\mathrm{R} 816$ are a hydrophobic fumed silica obtained by treating of Aerosil ${ }^{\circledR} 200$ with hexamethyldisilazane, octylsilane, and hexadecylsilane, respectively. Different length of aliphatic chain provided low cohesive intermolecular interactions between polymeric chain and functionalities at silica surface, which contributed to the low reinforcement effect in appropriate nanocomposites. Due to this, the best mechanical and rheological properties were found for composites with

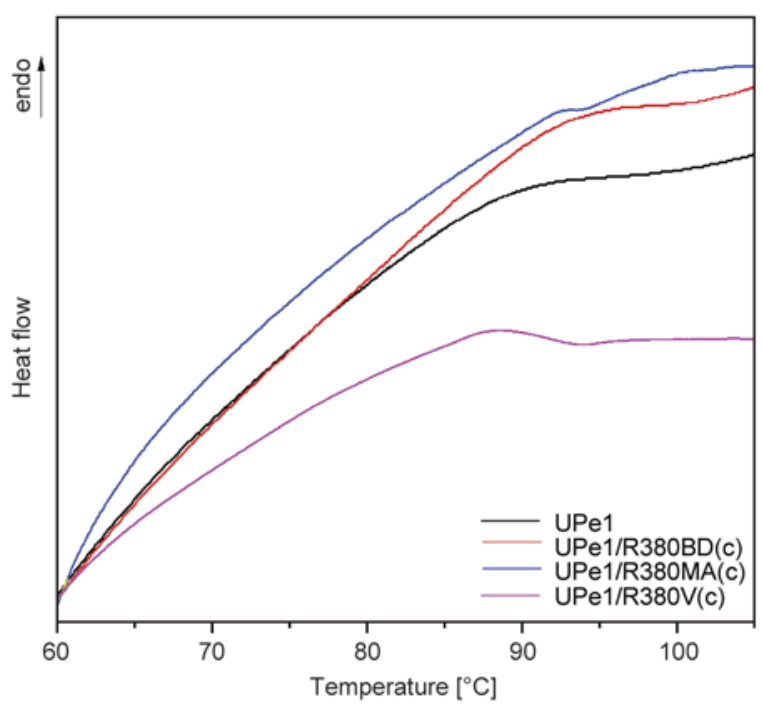

Figure 12. DSC curves obtained during heating at $10^{\circ} \mathrm{C} / \mathrm{min}$ of pure UPe1 and UPe1/R(c) nanocomposites
R200NPh nanofiller. High intensity $\pi, \pi$-stacking attractive intermolecular interaction between $N$ phenyl and terephthaloyl moieties provided effective physical cross-linking, and thus high reinforcing effect was found similar to the ones obtained in this work. However, reinforcing effect of R200NPh could not be achieved in UPe with EG and PG glycol, synthesized in this work, as for dipropylene glycol (DPG) based UPe [15]. Preliminary results indicate that lower flexibility of EG/PG fragments could not provide favorable conformational adaption to attain maximum intermolecular interactions in UPe2/ $\mathrm{R} 200 \mathrm{NPh}$ nanocomposite. Compared with the results presented in this work, with vinyl modified fumed silica Aerosil ${ }^{\circledR} 380$ (R380BD, R380MA and R380V), the best mechanical and rheological properties was found in composites with $\mathrm{R} 380 \mathrm{~V}$, i.e. UPe1/R380V and UPe2/R380V at all nanofiller loading. By incorporation of $1.0 \mathrm{wt} \%$ of silica $\mathrm{R} 380 \mathrm{~V}$ stress at break increase for $195-247 \%$ for UPeN/R380V(c) crosslinked nanocomposite. Presented results indicate that high performances nanocomposites based on UPe could be obtained by designing modification of nanofiller with preferably mono vinyl moiety, which could exert the lowest possible steric interference with polymeric chain.

Besides, in a previous work it was explained that comparison of the mechanical properties of the PET based UPes and nanocomposites with literature ones was difficult, due to the different experimental conditions, applied reinforcement materials, molecular weight of the UPe and styrene amount [15]. Commercial UPe resins with different styrene contents $(60,50$, and $40 \mathrm{wt} \%)$ exhibited reasonably lower stress at break value (11 MPa for cured UPe resin with $60 \mathrm{wt} \%$; $24 \mathrm{MPa}$ for cured UPe resin with $50 \mathrm{wt} \%$ and $37 \mathrm{MPa}$ for cured UPe resin with $40 \mathrm{wt} \%$ ) compared with UPes prepared in this work [49]. Comparing the silica content influence on the rheological and mechanical properties of the PET based nanocomposites with, for example, influence of fiber-glass content, the fiber-glass polyester resin composites showed higher values for stress at break and tensile modulus [50]. Presented results show that UPe resins obtained by polycondensation of maleic anhydride and products of PET glycolysis and nanocomposites are materials of comparable performance to the ones published in the literature, and thus presented methodology offers an applicable alternative for large scale production. 


\section{Conclusions}

In this work UPeN resins were used as polymer matrices, while surface modified fumed silica nanoparticles were used as nanofillers for the preparation of UPeN/R nanocomposites. The gel time of pure cured UPe2, obtained by EG azeotropic removal method, was shorter compared with UPe1 (classical method), while the maximum curing temperature was higher for UPe2 $\left(172.9^{\circ} \mathrm{C}\right)$. The lower gel time and maximum curing temperature were found for corresponding nanocomposites based on UPe2.

Mechanical testing results indicate that stress at break of all cured nanocomposites is higher than for pure UPeN, and increases with increasing modified silica content up to the $1 \mathrm{wt} \%$ in UPeN/R380(n), and after that small changes in mechanical properties was found. This result indicate that incorporation more than $2 \mathrm{wt} \%$ of modified silica contribute to lower dispersibility in polymeric matrix, i.e. strong cohesive force between nanofiller particles prevail. TEM analysis revealed that silica nanofiller formed chain-like aggregates which provided different extent of intermolecular interaction with cross-linked polymer network. Exceptional mechanical properties were obtained for UPe2/R380V(c): the value of stress at break and tensile modulus were $84 \mathrm{MPa}$ and $1.8 \mathrm{GPa}$, respectively. Similar results was obtained for impact strength testing, i.e. highest value of $\sigma_{\mathrm{i}}$ was obtained for both UPeN/R380V(c), while higher values of $\sigma_{\mathrm{f}}$ was obtained for UPeN/R380BD(c). In both case UPe1 resin showed higher value of impact and flexural strength.

Obtained DMA results indicated that the synthesis method of the UPe has more pronounced influence on the dynamic mechanical properties than type of $\mathrm{SiO}_{2}$ nanoparticles surface modification. Higher cross-linking density was observed for samples based on UPe2. The trend of glass transition temperature values obtained by DMA corresponds to $T_{\mathrm{g}}$ values obtained by DSC analysis.

\section{Acknowledgements}

The authors acknowledge financial support from Ministry of Education, Science and Technological development of Serbia, Project Nos. OI 172057. The authors would also like to pay special thanks to the Shimadzu Branch Belgrade (Shimadzu Corporation Japan) and Center for electron microscopy Faculty of Biology for the technical support.

\section{References}

[1] Karayannidis G. P., Achilias D. S.: Chemical recycling of poly(ethylene terephthalate). Macromolecular Materials and Engineering, 292, 128-146 (2007).

DOI: 10.1002/mame.200600341

[2] Mendes L. C., Dias M. L., Rodrigues T. C.: Chemical recycling of PET waste with multifunctional pentaerythrytol in the melt state. Journal of Polymers and the Environment, 19, 254-262 (2011).

DOI: $10.1007 / \mathrm{s} 10924-010-0276-\mathrm{y}$

[3] Zahedi A. R., Rafizadeh M., Taromi A. F.: Recycling of off-grade PET via partial alcoholysis to synthesize functionalized PET oligomer nanocomposites. Polymer Composites, 33, 1832-1839 (2012).

DOI: $10.1002 / p c .22312$

[4] Geyer B., Röhner S., Lorenz G., Kandelbauer A.: Improved thermostability and interfacial matching of nanoclay filler and ethylene vinyl alcohol matrix by silane-modification. Journal of Applied Polymer Science, 132, 41227/1-41227/11 (2015).

DOI: $10.1002 /$ app. 41227

[5] Atta A. M., Abdel-Raouf M. E., Elsaeed S. M., AbdelAzim A-A. A.: Mechanical characterization and chemical resistances of cured unsaturated polyester resins modified with vinyl ester resins based on recycled poly (ethylene terephthalate). Journal of Applied Polymer Science, 103, 3175-3182 (2007).

DOI: $10.1002 /$ app. 25196

[6] Ahmed N. M., Tawfik M. E., Ward A. A: Characterization of a polymer composite from treated kaolin and unsaturated polyester based on PET waste. Polymer Composites, 34, 1223-1234 (2013).

DOI: $10.1002 /$ pc.22529

[7] Torlakoğlu A., Güçlü G.: Alkyd-amino resins based on waste PET for coating applications. Waste Management, 29, 350-354 (2009).

DOI: $10.1016 /$ j.wasman.2008.02.018

[8] Güçlü G.: Alkyd resins based on waste PET for waterreducible coating applications. Polymer Bulletin, 64, 739-748 (2010). DOI: $10.1007 / \mathrm{s} 00289-009-0166-4$

[9] Klonos P., Panagopoulou A., Bokobza L., Kyritsis A., Peoglos V., Pissis P.: Comparative studies on effects of silica and titania nanoparticles on crystallization and complex segmental dynamics in poly(dimethylsiloxane). Polymer, 51, 5490-5499 (2010). DOI: $10.1016 /$ j.polymer.2010.09.054

[10] Dabrowska I., Fambri L., Pegoretti A., Slouf M., Vackova T., Kolarik J.: Spinning, drawing and physical properties of polypropylene nanocomposite fibers with fumed nanosilica. Express Polymer Letters, 9, 277290 (2015).

DOI: $10.3144 /$ expresspolymlett.2015.25 
[11] Kango S., Kalia S., Celli A., Njuguna J., Habibi Y., Kumar R.: Surface modification of inorganic nanoparticles for development of organic-inorganic nanocomposites - A review. Progress in Polymer Science, 38, 1232-1261 (2013).

DOI: 10.1016/j.progpolymsci.2013.02.003

[12] Srinivasa Moorthy S., Manonmani K.: Research on sliding wear behavior of $\mathrm{TiO}_{2}$ filled glass fiber reinforced polymer composite. Research Journal of Applied Sciences, Engineering and Technology, 7, 3356-3361 (2014).

[13] Jastrzêbska M., Janik H., Paukszta D.: The investigation of polyester composites filled by modified bentonite. Polimery, 59, 656-661 (2014).

DOI: $10.14314 /$ polimery.2014.656

[14] Wang Y-Q., Guo Y., Cui R-X., Wang Z-M., Wu Y-L.: Preparation and mechanical properties of nano-silica/ UPR polymer composite. Science and Engineering of Composite Materials, 21, 471-477 (2014).

DOI: $10.1515 / \mathrm{secm}-2013-0051$

[15] Rusmirović J. D., Radoman T., Džunuzović E. S., Džunuzović J. V., Markovski J., Spasojević P., Marinković A. D.: Effect of the modified silica nanofiller on the mechanical properties of unsaturated polyester resins based on recycled polyethylene terephthalate. Polymer Composites, in press (2015).

DOI: $10.1002 /$ pc. 23613

[16] May-Pat A., Avilés F., Toro P., Yazdani-Pedram M., Cauich-Rodríguez J. V.: Mechanical properties of Pet composites using multiwalled carbon nanotubes functionalized by inorganic and itaconic acids. Express Polymer Letters, 6, 96-106 (2012).

DOI: $10.3144 /$ expresspolymlett.2012.11

[17] Guo L., Xu X., Zhang Y., Zhang Z.: Effect of functionalized nanosilica on properties of polyoxymethylenematrix nanocomposites. Polymer Composites, 35, $127-$ 136 (2014).

DOI: $10.1002 /$ pc.22642

[18] Tong L., Pu Z., Chen Z., Huang X., Liu X.: Effect of nanosilica on the thermal, mechanical, and dielectric properties of polyarylene ether nitriles terminated with phthalonitrile. Polymer Composites, 35, 344-350 (2014). DOI: 10.1002/pc.22667

[19] Li Y., Han C., Zhang X., Bian J., Han L.: Rheology, mechanical properties, and biodegradation of poly $(\varepsilon-$ caprolactone)/silica nanocomposites. Polymer Composites, 34, 1620-1628 (2013).

DOI: $10.1002 /$ pc. 22562

[20] Castellano M., Turturro A., Marsano E., Conzatti L., Vicini S.: Hydrophobation of silica surface by silylation with new organo-silanes bearing a polybutadiene oligomer tail. Polymer Composites, 35, 1603-1613 (2014). DOI: $10.1002 /$ pc. 22813

[21] Hong R. Y., Fu H. P., Zhang Y. J., Liu L., Wang J., Li H. Z., Zheng Y.: Surface-modified silica nanoparticles for reinforcement of PMMA. Journal of Applied Polymer Science, 105, 2176-2184 (2007).

DOI: 10.1002/app.26164
[22] Spange S.: Silica surface modification by cationic polymerization and carbenium intermediates. Progress in Polymer Science, 25, 781-849 (2000).

DOI: $10.1016 / \mathrm{S} 0079-6700(00) 00014-9$

[23] Kim K-J., White J. L.: Silica surface modification using different aliphatic chain length silane coupling agents and their effects on silica agglomerate size and processability. Composite Interfaces, 9, 541-556 (2002).

DOI: $10.1163 / 15685540260494119$

[24] Savin D. A., Pyun J., Patterson G. D., Kowalewski T., Matyjaszewski K.: Synthesis and characterization of silica-graft-polystyrene hybrid nanoparticles: Effect of constraint on the glass-transition temperature of spherical polymer brushes. Journal of Polymer Science Part B: Polymer Physics, 40, 2667-2676 (2002).

DOI: $10.1002 /$ polb.10329

[25] Li N., Luo P., Liu K., Chen L., Wang K., Chen F., Fu Q.: Preparation and properties of poly(ethylene terephthalate)/inorganic whiskers composites. Journal of Applied Polymer Science, 121, 604-611 (2011).

DOI: 10.1002/app.33729

[26] Zhand Y., Lv F., Ke S., Yu L., Huang H., Chan H. L. W.: Effect of hollow structure and covalent bonding on the mechanical properties of core-shell silica nanoparticles modified poly(methyl acrylate) composites. Materials Chemistry and Physics, 129, 77-82 (2011).

DOI: $10.1016 / \mathrm{j}$. matchemphys.2011.03.057

[27] Luo Z., Hong R. Y., Xie H. D., Feng W G.: One-step synthesis of functional silica nanoparticles for reinforcement of polyurethane coatings. Powder Technology, 218, 23-30 (2012).

DOI: 10.1016/j.powtec.2011.11.023

[28] Hamad A.: Preparation and characterization of some unsaturated polyester alkyds based on terephthalic and isophthalic acids. PhD Thesis, Loughborough University Institutional Repository (1980).

[29] ISO 4326:1992: Non-ionic surface active agents - Polyethoxylated derivatives - Determination of hydroxyl value - Acetic anhydride method (1992).

[30] ASTM D3644: Standard test method for acid number of styrene-maleic anhydride resins (2012).

[31] EN 14103: Fat and oil derivatives - Fatty acid methyl esters (fame) - Determination of ester and linolenic acid methyl ester contents (2003).

[32] ASTM D1200: Standard test method for viscosity by ford viscosity cup (2014).

[33] ASTM D2471-99: Standard test method for gel time and peak exothermic temperature of reacting thermosetting resins (2008).

[34] ASTM D882: Standard test method for tensile properties of thin plastic sheeting (2009).

[35] ASTM D790: Standard test methods for flexural properties of unreinforced and reinforced plastics and electrical insulating materials (2010).

[36] ASTM D256: Standard test methods for determining the izod pendulum impact resistance of plastics (2006). 
[37] Patel M. R., Patel J. V., Sinha V. K.: Polymeric precursors from PET waste and their application in polyurethane coatings. Polymer Degradation and Stability, 90, 111-115 (2005).

DOI: $10.1016 /$ j.polymdegradstab.2005.02.017

[38] Güçlü G., Kaşgöz A., Özbudak S., Özgümüs S., Orbay M.: Glycolysis of poly(ethylene terephthalate) wastes in xylene. Journal of Applied Polymer Science, 69, 2311-2319 (1998).

DOI: 10.1002/(SICI)1097-4628(19980919)69:12<2311 $\because$ AID-APP2>3.0.CO;2-B

[39] Stojanović D., Orlović A., Marković S., Radmilović V., Uskoković P. S., Aleksić R.: Nanosilica/PMMA composites obtained by the modification of silica nanoparticles in a supercritical carbon dioxide-ethanol mixture. Journal of Materials Science, 44, 6223-6232 (2009). DOI: $10.1007 / \mathrm{s} 10853-009-3842-8$

[40] Zahedi A. R., Rafizadeh M., Ghafarian S. R.: Unsaturated polyester resin via chemical recycling of off-grade poly(ethylene terephthalate). Polymer International, 58, 1084-1091 (2009). DOI: $10.1002 /$ pi.2637

[41] Ou Y-C., Yu Z-Z., Vidal A., Donnet J. B.: Effects of alkylation of silicas on interfacial interaction and molecular motions between silicas and rubbers. Journal of Applied Polymer Science, 59, 1321-1328 (1996).

DOI: $10.1002 /($ SICI) 1097-4628(19960222)59:8<1321 $\because$ AID-APP16>3.0.CO;2-8

[42] Guo Z., Pereira T., Choi O., Wang Y., Hahn H. T.: Surface functionalized alumina nanoparticle filled polymeric nanocomposites with enhanced mechanical properties. Journal of Materials Chemistry, 16, 2800-2808 (2006). DOI: $10.1039 / \mathrm{B} 603020 \mathrm{C}$
[43] Kanimozhi K., Prabunathan P., Selvaraj V., Alagar M.: Vinyl silane-functionalized rice husk ash-reinforced unsaturated polyester nanocomposites. RSC Advances, 4, 18157-18163 (2014). DOI: $10.1039 / \mathrm{c} 4 \mathrm{ra} 01125 \mathrm{~b}$

[44] Kutz M.: Applied plastics engineering handbook: Processing and materials. Elsevier, Waltham (2011).

[45] Crawford D. M., Escarsega J. A.: Dynamic mechanical analysis of novel polyurethane coating for military applications. Thermochimica Acta, 357-358, 161-168 (2000). DOI: 10.1016/S0040-6031(00)00385-3

[46] Džunuzović E., Tasić S., Božić B., Jeremić K., Dunjic B.: Photoreactive hyperbranched urethane acrylates modified with a branched saturated fatty acid. Reactive and Functional Polymers, 66, 1097-1105 (2006). DOI: 10.1016/j.reactfunctpolym.2006.01.016

[47] Kannurpatti A. R., Anseth J. W., Bowman C. N.: A study of the evolution of mechanical properties and structural heterogeneity of polymer networks formed by photopolymerizations of multifunctional (meth)acrylates. Polymer, 39, 2507-2513 (1998). DOI: $10.1016 / \mathrm{S} 0032-3861(97) 00585-5$

[48] Worzakowska M.: Studies on the cure reaction and relationship between network structure/thermal properties of styrene copolymers based on adypic/sebacic acid modified unsaturated (epoxy) polyesters. Macromolecular Symposia, 296, 254-264 (2010). DOI: $10.1002 /$ masy.201051036

[49] Osman E., Vakhguelt A., Sbarski I., Mutasher S.: Curing behaviour and tensile properties of unsaturated polyester containing various styrene concentrations. Malaysian Polymer Journal, 7, 46-55 (2012).

[50] Pepper T.: Polyester resin. Ashland Chemical Company, Lexington (2003). 